\title{
LONG RUN AND CYCLICAL DYNAMICS IN THE US STOCK MARKET
}

\author{
Guglielmo Maria Caporale \\ Brunel University, London
}

\author{
Luis A. Gil-Alana \\ University of Navarra
}

June 2005

\begin{abstract}
This paper examines the long-run dynamics and the cyclical structure of the US stock market using fractional integration techniques. We implement a version of the tests of Robinson (1994a), which enables one to consider unit roots with possibly fractional orders of integration both at the zero (long-run) and the cyclical frequencies. We examine the following series: inflation, real risk-free rate, real stock returns, equity premium and price/dividend ratio, annually from 1871 to 1993. When focusing exclusively on the long-run or zero frequency, the estimated order of integration varies considerably, but nonstationarity is found only for the price/dividend ratio. When the cyclical component is also taken into account, the series appear to be stationary but to exhibit long memory with respect to both components in almost all cases. The exception is the price/dividend ratio, whose order of integration is higher than 0.5 but smaller than 1 for the long-run frequency, and is between 0 and 0.5 for the cyclical component. Also, mean reversion occurs in all cases. Finally, we use six different criteria to compare the forecasting performance of the fractional (at both zero and cyclical frequencies) models with others based on fractional and integer differentiation only at the zero frequency. The results show that the former outperform the others in a number of cases.
\end{abstract}

Keywords: Stock Market, Fractional Cycles, Long Memory, Gegenbauer Processes

JEL classification: C22, G12, G14

Corresponding author: Professor Guglielmo Maria Caporale, Brunel Business School, Brunel University, Uxbridge, Middlesex UB8 3PH, UK. Tel.: +44 (0)1895 266713. Fax: +44 (0)1895 269770. Email: Guglielmo-Maria.Caporale@brunel.ac.uk

We are grateful to participants in the 2004 European Meeting of the Econometric Society, Madrid, Spain, 19-24 August 2004, and the V Encuentro Internacional de Finanzas, Santiago, Chile, 19-21 January 200, for useful comments and suggestions. 
The Efficient Market Hypothesis (EMH) has been tested in numerous empirical studies by trying to establish whether stock prices are I(1) or stock market returns $\mathrm{I}(0)$ series. This is based on the idea that it should not be possible to make systematic profits above transaction costs and risk premia, and therefore returns should be unpredictable. Mean reversion is then seen as inconsistent with equilibrium asset pricing models (see the survey by Forbes, 1996). Note, however, that if risk factors change systematically over the business cycle, expected returns should also be time-varying. Similarly, allowing for business cycle variation and short-range dependence might also result in rejecting long memory in stock prices (see Lo, 1991). In general, as stressed in Caporale and Gil-Alana (2002), the unit root tests normally employed impose too restrictive assumptions on the behaviour of the series of interest, in addition to having low power. That study suggests instead using tests which allow for fractional alternatives (see Robinson, 1994a, 1995a,b), and finds that US real stock returns are close to being I(0) (which raises the further question whether the shocks are autocorrelated, with the implication that markets are not efficient). Fractional integration models have also been used for inflation and interest rates (see, e.g., Shea, 1991; Backus and Zhin, 1993; Hassler and Wolters, 1995; Baillie et al., 1996, etc.).

However, it has become increasingly clear that the cyclical component of economic and financial series is also very important. This has been widely documented, especially in the case of business cycles, for which non-linear (Beaudry and Koop, 1993, Pesaran and Potter, 1997) or fractionally ARIMA (ARFIMA) models (see Candelon and Gil-Alana, 2004) have been proposed. Furthermore, it has been argued that cycles should be modelled as an additional component to the trend and the seasonal structure of the series (see Harvey, 1985, Gray et al, 1989). The available evidence suggests that the periodicity of the series ranges between five and ten years, in most cases a periodicity of about six years being estimated (see, e.g., Baxter and King, 1999; Canova, 1998; King and Rebelo, 1999). 
In view of these findings, the present paper extends the earlier work by Caporale and Gil-Alana (2002) by adopting a modelling approach which, instead of considering exclusively the component affecting the long-run or zero frequency, also takes into account the cyclical structure. Furthermore, the analysis is carried out for the US inflation rate, real risk-free rate, equity premium and price/dividend ratio, in addition to real stock returns. More precisely, we use a procedure due to Robinson (1994a), which enables one to test simultaneously for roots with possibly fractional orders of integration at both zero and the cyclical frequencies. This approach has several distinguishing features compared with other methods, the most noticeable one being its standard null and local limit distributions. ${ }^{1}$ Moreover, it does not require Gaussianity (a condition rarely satisfied in financial time series), a moment condition only of order two being sufficient. Also, modelling simultaneously the zero and the cyclical frequencies can solve at least to some extent the problem of misspecification that might arise with respect to these two frequencies. We are able to show that our proposed method represents an appealing alternative to the increasingly popular ARIMA (ARFIMA) specifications found in the literature. It is also consistent with the widely adopted practice of modelling many economic series as two separate components, namely a secular or growth component and a cyclical one. The former, assumed in most cases to be nonstationary, is thought to be driven by growth factors, such as capital accumulation, population growth and technology improvements, whilst the latter, assumed to be covariance stationary, is generally associated with fundamental factors which are the primary cause of movements in the series. ${ }^{2}$

The structure of the paper is as follows. Section 1 briefly describes the statistical model. Section 2 introduces the version of the Robinson's (1994a) tests used for the empirical analysis. Section 3 discusses an application to annual data on several US stock market series for the time period 1871 - 1993. Section 4 is concerned with model selection for each time series, and the preferred specifications are compared with other more classical representations. In this section 
we focus in particular on the US inflation and the price/dividend ratio series. Section 5 contains some concluding comments.

\section{The statistical model}

Let us suppose that $\left\{\mathrm{y}_{\mathrm{t}}, \mathrm{t}=1,2, \ldots, \mathrm{n}\right\}$ is the time series we observe, which is generated by the model:

$$
(1-L)^{d_{1}}\left(1-2 \cos w L+L^{2}\right)^{d_{2}} y_{t}=u_{t}, \quad t=1,2, . .
$$

where $\mathrm{L}$ is the lag operator $\left(\mathrm{Ly} \mathrm{y}_{\mathrm{t}}=\mathrm{y}_{\mathrm{t}-1}\right), \mathrm{w}$ is a given real number, $\mathrm{u}_{\mathrm{t}}$ is $\mathrm{I}(0)^{3}$ and $\mathrm{d}_{1}$ and $\mathrm{d}_{2}$ can be real numbers. Let us first consider the case of $d_{2}=0$. Then, if $d_{1}>0$, the process is said to be long memory at the long-run or zero frequency, also termed 'strong dependent', because of the strong association between observations widely separated in time. Note that the first polynomial in (1) can be expressed in terms of its Binomial expansion, such that for all real $d_{1}$ :

$$
(1-L)^{d_{1}}=\sum_{j=0}^{\infty}\left(\begin{array}{l}
d_{1} \\
j
\end{array}\right)(-1)^{j} L^{j}=1-d_{1} L+\frac{d_{1}\left(d_{1}-1\right)}{2} L^{2}-\ldots
$$

These processes were initially introduced by Granger (1980, 1981) and Hosking (1981), and were theoretically justified in terms of aggregation by Robinson (1978) and Granger (1980), the argument being that cross-section aggregation of a large number of $\mathrm{AR}(1)$ processes with heterogeneous AR coefficients may create long memory. Parke (1999) uses a closely related discrete time error duration model, while Diebold and Inoue (2001) relate fractional integration with regime switching models. ${ }^{4}$ The differencing parameter $\mathrm{d}_{1}$ plays a crucial role from both economic and statistical viewpoints. Thus, if $\mathrm{d}_{1} \in(0,0.5)$, the series is covariance stationary and mean-reverting, with shocks disappearing in the long run; if $d_{1} \in[0.5,1)$, the series is no longer stationary but still mean-reverting, while $d_{1} \geq 1$ means nonstationarity and non-meanreversion. It is therefore crucial to examine if $d_{1}$ is smaller than or equal to or higher than 1 . For example, if $\mathrm{d}_{1}<1$, there is less need for policy action than if $\mathrm{d}_{1} \geq 1$, since the series will return 
to its original level some time in the future. On the contrary, if $\mathrm{d}_{1} \geq 1$, shocks will be permanent, and active policies are required to bring the variable back to its original long-term projection. In fact, this is one of the most hotly debated topics in empirical finance. Lo and MacKinlay (1988) and Poterba and Summers (1988) used variance-ratio tests and found evidence of mean reversion in stock returns. On the contrary, Lo (1991) used a generalised form of rescaled range (R/S) statistic and found no evidence against the random walk hypothesis for the stock indices. Other papers examining the persistence of shocks in financial time series are Lee and Robinson (1996), Fiorentini and Sentana (1998) and May (1999).

Let us now consider the case of $d_{1}=0$ and $d_{2}>0$. The process is then said to exhibit long memory at the cyclical frequency. This model was examined by Gray et al $(1989,1994)$, who showed that the series is stationary if $|\cos w|<1$ and $\mathrm{d}_{2}<0.50$ or if $|\cos \mathrm{w}|=1$ and $\mathrm{d}_{2}$ $<0.25$. They also showed that the second polynomial in (1) can be expressed in terms of the Gegenbauer polynomial $C_{j, d_{2}}$, such that, defining $\mu=\cos \mathrm{w}$,

$$
\left(1-2 \mu L+L^{2}\right)^{-d_{2}}=\sum_{j=0}^{\infty} C_{j, d_{2}}(\mu) L^{j}
$$

for all $\mathrm{d}_{2} \neq 0$, where

$$
C_{j, d_{2}}(\mu)=\sum_{k=0}^{[j / 2]} \frac{(-1)^{k}\left(d_{2}\right)_{j-k}(2 \mu)^{j-2 k}}{k !(j-2 k) !} ; \quad\left(d_{2}\right)_{j}=\frac{\Gamma\left(d_{2}+j\right)}{\Gamma\left(d_{2}\right)}
$$

where $\Gamma(\mathrm{x})$ represents the Gamma function and a truncation will be required in (2) to make the polynomial operational. ${ }^{5}$ Of particular interest is the case of $\mathrm{d}_{2}=1$, i.e. when the process contains unit root cycles; its performance in the context of macroeconomic time series was examined, for example, by Bierens $(2001) .{ }^{6}$ Such processes, for which the crucial issue is to have a spectral density with a peak at $(0, \pi]$, were later extended to the case of a finite number of peaks by Giraitis and Leipus (1995) and Woodward et al (1998) (see also Gray et al (1989) and Robinson (1994a)). The economic implications in (2) are similar to the previous case of 
long memory at the zero frequency. Thus, if $\mathrm{d}_{2}<1$, shocks affecting the cyclical part will be mean reverting, while $\mathrm{d}_{2} \geq 1$ implies an infinite degree of persistence of the shocks. This type of model for the cyclical component has not been previously used for financial time series, though Robinson (2001, pp. 212-213) suggests its adoption in the context of complicated autocovariance structures.

\section{The testing procedure}

Following Bhargava (1986), Schmidt and Phillips (1992) and others in the parameterisation of unit-root models, Robinson (1994a) considers the regression model:

$$
y_{t}=\beta^{\prime} z_{t}+x_{t} \quad t=1,2, \ldots,
$$

where $\mathrm{y}_{\mathrm{t}}$ is the observed time series; $\mathrm{z}_{\mathrm{t}}$ is a $(\mathrm{kx} 1)$ vector of deterministic regressors that may include, for example, an intercept, (e.g., $\left.z_{t} \equiv 1\right)$, or an intercept and a linear time trend (in the case of $\left.z_{t}=(1, t)^{T}\right) ; \beta$ is a $(k x 1)$ vector of unknown parameters; and the regression errors $x_{t}$ are such that:

$$
\rho(L ; \theta) x_{t}=u_{t} \quad t=1,2, \ldots,
$$

where $\rho$ is a given function which depends on $\mathrm{L}$, and the (px1) parameter vector $\theta$, adopting the form:

$$
\rho(L ; \theta)=(1-L)^{d_{1}+\theta_{1}}\left(1-L^{s}\right)^{d^{s}+\theta^{s}} \prod_{j=2}^{p-1}\left(1-2 \cos w L+L^{2}\right)^{d_{j}+\theta_{j}}
$$

for real given numbers $d_{1}, d^{s}, d_{2}, \ldots d_{p-1}$, integer $p$, and where $u_{t}$ is $I(0)$. Note that the second polynomial in (5) refers to the case of seasonality (i.e. $s=4$ in case of quarterly data, and $s=12$ with monthly observations). Under the null hypothesis, defined by:

$$
\mathrm{H}_{\mathrm{o}}: \quad \theta=0
$$

(5) becomes: 


$$
\rho(L ; \theta=0)=\rho(L)=(1-L)^{d_{1}}\left(1-L^{s}\right)^{d^{s}} \prod_{j=2}^{p-1}\left(1-2 \cos w L+L^{2}\right)^{d_{j}} .
$$

This is a very general specification that makes it possible to consider different models under the null. For example, if $\mathrm{d}_{1}=1$ and $\mathrm{d}^{\mathrm{s}}, \mathrm{d}_{\mathrm{j}}=0$ for $\mathrm{j} \geq 2$, we have the classical unit-root models (Dickey and Fuller, 1979, Phillips, 1987; Phillips and Perron, 1988, Kwiatkowski et al., 1992, etc.), whilst, if $\mathrm{d}_{1}$ is a real number, we obtain the fractional models examined in Diebold and Rudebusch (1989), Baillie (1996) and others. Similarly, if $d^{s}=1$ and $d_{j}=0$ for all $j$, we have the seasonal unit-root model (Dickey, Hasza and Fuller, 1984, Hyllerberg et al., 1990, etc.) and, if $\mathrm{d}^{\mathrm{s}}$ is real, the seasonal fractional model analysed in Porter-Hudak (1990). If $\mathrm{d}_{3}=1$ and $\mathrm{d}^{\mathrm{s}}, \mathrm{d}_{\mathrm{j}}=$ 0 for $\mathrm{j} \neq 3$, the model becomes the unit root cycles of Ahtola and Tiao (1987) and Bierens (2001), and if $d_{3}$ is real, the Gegenbauer processes examined by Gray et al. (1989, 1994), Ferrara and Guegan (2001), etc.

In this paper we are concerned with both the long run and the cyclical structure of the series, and thus we assume that $\mathrm{d}^{\mathrm{s}}=0$ and $\mathrm{p}=3$. In such a case (5) can be expressed as:

$$
\rho(L ; \theta)=(1-L)^{d_{1}+\theta_{1}}\left(1-2 \cos w L+L^{2}\right)^{d_{2}+\theta_{2}},
$$

and, similarly, (7) becomes:

$$
\rho(L)=(1-L)^{d_{1}}\left(1-2 \cos w L+L^{2}\right)^{d_{2}} .
$$

Here, $d_{1}$ represents the degree of integration at the long run or zero frequency (i.e., the stochastic trend), while $\mathrm{d}_{2}$ affects the cyclical component of the series.

Next we describe the test statistic. We observe $\left\{\left(\mathrm{y}_{\mathrm{t}}, \mathrm{z}_{\mathrm{t}}\right), \mathrm{t}=1,2, \ldots \mathrm{n}\right\}$, and suppose that the $\mathrm{I}(0) \mathrm{u}_{\mathrm{t}}$ in (4) have parametric spectral density given by:

$$
f(\lambda ; \tau)=\frac{\sigma^{2}}{2 \pi} g(\lambda ; \tau), \quad-\pi<\lambda \leq \pi
$$

where the scalar $\sigma^{2}$ is known and $\mathrm{g}$ is a function of known form, which depends on frequency $\lambda$ and the unknown (qx1) vector $\tau$. Based on $\mathrm{H}_{\mathrm{o}}(6)$, the residuals in (3), (4) and (9) are: 


$$
\hat{u}_{t}=(1-L)^{d_{1}}\left(1-2 \cos w L+L^{2}\right)^{d_{2}} y_{t}-\hat{\beta}^{\prime} s_{t},
$$

where

$$
\hat{\beta}=\left(\sum_{t=1}^{n} s_{t} s_{t}{ }^{\prime}\right)^{-1} \sum_{t=1}^{n} s_{t}(1-L)^{d_{1}}\left(1-2 \cos w L+L^{2}\right)^{d_{2}} y_{t}, \quad s_{t}=(1-L)^{d_{1}}\left(1-2 \cos w L+L^{2}\right)^{d_{2}} Z_{t} .
$$

Unless $\mathrm{g}$ is a completely known function (e.g., $\mathrm{g} \equiv 1$, as when $\mathrm{u}_{\mathrm{t}}$ is white noise), we need to estimate the nuisance parameter $\tau$, for example by $\hat{\tau}=\arg \min { }_{\tau \in T}{ }^{*} \sigma^{2}(\tau)$, where $\mathrm{T}^{*}$ is a suitable compact subset of $\mathrm{R}^{\mathrm{q}}$ Euclidean space, and

$$
\sigma^{2}(\tau)=\frac{2 \pi}{n} \sum_{s=1}^{n-1} g\left(\lambda_{s} ; \tau\right)^{-1} I_{\hat{u}}\left(\lambda_{s}\right), \text { with } \quad I_{\hat{u}}\left(\lambda_{s}\right)=\left|(2 \pi n)^{-1 / 2} \sum_{t=1}^{n} \hat{u}_{t} e^{i \lambda_{s} t}\right|^{2} ; \quad \lambda_{s}=\frac{2 \pi s}{n}
$$

The test statistic, which is derived through the Lagrange Multiplier (LM) principle, takes the form:

$$
\hat{R}=\hat{r}^{\prime} \hat{r} ; \quad \hat{r}=\left(\frac{\sqrt{n}}{\hat{\sigma}^{2}}\right) \hat{A}^{-1 / 2} \hat{a}
$$

where $\mathrm{n}$ is the sample size, and

$$
\begin{gathered}
\hat{a}=\frac{-2 \pi}{n} \sum_{s}^{*} \psi\left(\lambda_{s}\right) g\left(\lambda_{s} ; \hat{\tau}\right)^{-1} I\left(\lambda_{s}\right) ; \quad \hat{\sigma}^{2}=\sigma^{2}(\hat{\tau})=\frac{2 \pi}{n} \sum_{s=1}^{n-1} g\left(\lambda_{s} ; \hat{\tau}\right)^{-1} I\left(\lambda_{s}\right), \\
\hat{A}=\frac{2}{n}\left(\sum_{s}^{*} \psi\left(\lambda_{s}\right) \psi\left(\lambda_{s}\right)^{\prime}-\sum_{s}^{*} \psi\left(\lambda_{s}\right) \hat{\varepsilon}\left(\lambda_{s}\right)^{\prime}\left(\sum_{s}^{*} \hat{\varepsilon}\left(\lambda_{s}\right) \hat{\varepsilon}\left(\lambda_{s}\right)^{\prime}\right)^{-1} \sum_{s}^{*} \hat{\varepsilon}\left(\lambda_{s}\right) \psi\left(\lambda_{s}\right)^{\prime}\right) \\
\psi\left(\lambda_{s}\right)^{\prime}=\left[\psi_{1}\left(\lambda_{s}\right), \psi_{2}\left(\lambda_{s}\right)\right] ; \quad \hat{\varepsilon}\left(\lambda_{s}\right)=\frac{\partial}{\partial \tau} \log g\left(\lambda_{s} ; \hat{\tau}\right) ; \\
\psi_{1}\left(\lambda_{s}\right)=\log \left|2 \sin \frac{\lambda_{s}}{2} ; ; \quad \psi_{2}\left(\lambda_{s}\right)=\log \right| 2\left(\cos \lambda_{s}-\cos w\right) \mid .
\end{gathered}
$$

and the sums in $\hat{a}$ and $\hat{A}$ in the above expressions are over all frequencies except those which are unbounded. Based on $\mathrm{H}_{\mathrm{o}}$ (6), Robinson (1994a) established that, under certain regularity conditions: ${ }^{7}$ 


$$
\hat{R} \rightarrow_{d} \chi_{2}^{2}, \quad \text { as } \quad n \rightarrow \infty
$$

Thus, as shown by Robinson (1994a), unlike in other procedures, we are in a classical largesample testing situation, and furthermore the tests are efficient in the Pitman sense against local departures from the null. ${ }^{8}$ Because $\hat{R}$ involves a ratio of quadratic forms, its exact null distribution could have been calculated under Gaussianity via Imhof's algorithm. However, a simple test is approximately valid under much wider distributional assumptions: a test of (6) will reject $\mathrm{H}_{\mathrm{o}}$ against the alternative $\mathrm{H}_{\mathrm{a}}: \theta \neq 0$ if $\hat{R}>\chi_{2, \alpha}^{2}$, where $\operatorname{Prob}\left(\chi_{2, \alpha}^{2}>\chi_{2}^{2}\right)=\alpha$. A similar version of Robinson's (1994a) tests (with $\mathrm{d}_{1}=0$ ) was examined in Gil-Alana (2001), where its performance in the context of unit-root cycles was compared with that of the Ahtola and Tiao's (1987) tests, the results showing that the former outperform the latter in a number of cases. Other versions of his tests have been successfully applied to raw time series in Gil-Alana and Robinson $(1997,2001)$ to test for I(d) processes with the roots occurring at zero and the seasonal frequencies respectively. However, this is the first empirical finance application testing simultaneously for the roots at zero and the cyclical frequencies, a statistical approach which is shown in the present paper to represent a convenient alternative to the more conventional ARIMA (ARFIMA) specifications used for the parametric modelling of many time series.

\section{An empirical application to the US stock market}

Our dataset includes annual series for US inflation, real risk-free rate, real stock returns, equity premium and price/dividend ratio from 1871 to 1993 , and is a slightly updated version of the dataset used in Cecchetti et al (1990) (see that paper for further details on sources and definitions).

(Insert Figure 1 about here) 
Figure 1 contains plots of the original series with their corresponding correlograms and periodograms. All of them, with the exception of the price/dividend ratio, appear to be stationary. However, deeper inspection of the correlograms shows that there are significant values even at some lags relatively distant from zero, along with slow decay and/or cyclical oscillation in some cases, which could indicate not only fractional integration at the zero frequency but also cyclical dependence. Similarly, the periodograms also have peaks at frequencies other than zero. For the price/dividend ratio, the slow decay in the correlogram clearly suggests that the series is not $\mathrm{I}(0)$ stationary.

\section{(Insert Figure 2 about here)}

Figure 2 displays similar plots for the first differenced data. The correlograms and periodograms now strongly suggest that all series are overdifferenced with respect to the 0 frequency. On the other hand, there are significant peaks in the periodograms at frequencies different from zero. In view of this, it might be of interest to examine more in depth the behaviour of these series using a fractional model at both the zero and the cyclical frequencies.

As a first step, we focus on the long run or zero frequency and implement a simple version of Robinson's (1994a) test, which is based on a model given by (3) and (4), with $\mathrm{z}_{\mathrm{t}}=$ $(1, t)^{\mathrm{T}}, \mathrm{t} \geq 1,(0,0)^{\mathrm{T}}$ otherwise, and $\rho(\mathrm{L} ; \theta)=(1-\mathrm{L})^{\mathrm{d}+\theta}$. Thus, under $\mathrm{H}_{\mathrm{o}}(6)$, we test the model:

$$
\begin{aligned}
& y_{t}=\beta_{0}+\beta_{1} t+x_{t}, \quad t=1,2, \ldots \\
& (1-L)^{d} x_{t}=u_{t}, \quad t=1,2, \ldots,
\end{aligned}
$$

for values $d=0,(0.01), 2$, and different types of disturbances. In such a case, the test statistic greatly simplifies, taking the form given by (11), with $\psi\left(\lambda_{s}\right)$ being exclusively defined by $\psi_{1}\left(\lambda_{\mathrm{s}}\right)$ and $\hat{u}_{t}=(1-L)^{d} y_{t}-\hat{\beta}^{\prime} w_{t}$. The null limit distribution will then be a $\chi_{1}^{2}$ distribution. However, if $\rho(L ; \theta)=(1-L)^{\mathrm{d}+\theta}$, then $\mathrm{p}=1$, and therefore we can consider one-sided tests based on $\hat{r}=\sqrt{\hat{R}}$, with a standard $\mathrm{N}(0,1)$ distribution: an approximate one-sided $100 \alpha \%$ level 
test of $H_{o}(6)$ against the alternative: $H_{a}: \theta>0(\theta<0)$ will be given by the rule: "Reject $H_{o}$ if $\hat{r}$ $>\mathrm{z}_{\alpha}\left(\hat{r}<-\mathrm{z}_{\alpha}\right)$ ", where the probability that a standard normal variate exceeds $\mathrm{z}_{\alpha}$ is $\alpha$. Note that testing the null hypothesis with $d=1$ means that this becomes a classical unit-root test of the same form as those proposed by Dickey and Fuller (1979) and others. However, instead of using autoregressive (AR) alternatives of the form: $(1-(1+\theta) L) x_{t}=u_{t}$, we use fractional alternatives. Moreover, the use of AR alternatives results in a dramatic change in the asymptotic behaviour of the tests: if $\theta<0, x_{t}$ is stationary; it contains a unit root if $\theta=0$, and it becomes nonstationary and explosive for $\theta>0$. On the contrary, under fractional alternatives of the form as in (14), the behaviour of $\mathrm{x}_{\mathrm{t}}$ is smooth across $\mathrm{d}$, this being the intuitive reason for its standard asymptotic behaviour.

The results presented in Table 1 correspond to the 95\%-confidence intervals of the values of $\mathrm{d}$ for which $\mathrm{H}_{\mathrm{o}}$ (6) cannot be rejected, using white noise disturbances. ${ }^{9}$ We examine separately the cases of $\beta_{0}=\beta_{1}=0$ a priori (i.e., with no regressors in the undifferenced model (13)); $\beta_{0}$ unknown and $\beta_{1}=0$ (with an intercept); and $\beta_{0}$ and $\beta_{1}$ unknown (an intercept and a linear time trend). The inclusion of a linear time trend may appear unrealistic in the case of financial time series. However, it should be noted that in the context of fractional (or integer) differences, the time trend disappears in the long run. For example, suppose that $u_{t}$ in (14) is white noise. Then, testing $H_{o}(6)$ in (13) and (14) with $d=1$, the series becomes, for $t>1$, a pure random walk process if $\beta_{1}=0$, and a random walk with an intercept if both $\beta_{0}$ and $\beta_{1}$ are unknown. ${ }^{10}$ The results differ substantially from one series to another. For instance, for inflation and the real risk-free rate the values are always higher than 0 but smaller than 0.5 , oscillating between 0.07 (inflation rate with a linear trend) and 0.49 (real risk-free rate with no regressors). For real stock returns and equity premium, the values of $d$ for which $H_{o}(6)$ cannot be rejected oscillate widely around 0 , ranging between -0.18 (equity premium with a linear trend) and 0.14 (stock returns with no regressors). Finally, for the price/dividend ratio all the 
non-rejection values are higher than 0.5 , implying nonstationarity with respect to the zero frequency.

\section{(Insert Tables 1 and 2 about here)}

The significant results in Table 1 may be partly due to the fact that $\mathrm{I}(0)$ autocorrelation in $\mathrm{u}_{\mathrm{t}}$ has not been taken into account. Thus, we also performed the tests imposing $\operatorname{AR}(1)$ disturbances (see Table 2). Higher AR orders were also tried and the results were very similar. For all series, except the price/dividend ratio, the values oscillate around 0 , implying that the series may be $\mathrm{I}(0)$ stationary. However, for the price/dividend ratio, the values are still above 0 , ranging from 0.13 (with a linear time trend) to 0.83 (in the case of no regressors). Comparing the results of Table 2 with those of Table 1 (white noise $u_{t}$ ), we can see that the orders of integration are smaller by about 0.20 when autocorrelation is allowed for. This might reflect the fact that the estimates of the AR coefficients are Yule-Walker, which entails AR roots that, although automatically less than one in absolute value, can be arbitrarily close to one. Hence, they might compete with the order of integration at the zero frequency when describing the behaviour at such a frequency.

It may also be of interest to examine d, independently of the way of modelling the I(0) disturbances, at the same zero frequency. For this purpose, we use a semiparametric Whittle procedure due to Robinson (1995a), which we now describe. It is essentially a local 'Whittle estimator' in the frequency domain, using a band of frequencies that degenerates to zero. The estimator is implicitly defined by:

$$
\begin{gathered}
\hat{d}=\arg \min _{d}\left(\log \overline{C(d)}-2 d \frac{1}{m} \sum_{s=1}^{m} \log \lambda_{s}\right), \\
\overline{C(d)}=\frac{1}{m} \sum_{s=1}^{m} I\left(\lambda_{s}\right) \lambda_{s}^{2 d}, \quad \lambda_{s}=\frac{2 \pi s}{n}, \quad \frac{m}{n} \rightarrow 0,
\end{gathered}
$$

where $\mathrm{I}\left(\lambda_{\mathrm{s}}\right)$ is the periodogram of the raw time series, $\mathrm{x}_{\mathrm{t}}$, given by: 


$$
I\left(\lambda_{s}\right)=\frac{1}{2 \pi n}\left|\sum_{t=1}^{n} x_{t} e^{i \lambda_{s} t}\right|^{2},
$$

and $\mathrm{d} \in(-0.5,0.5) .{ }^{11}$ Under finiteness of the fourth moment and other mild conditions, Robinson (1995a) proved that:

$$
\sqrt{m}\left(\hat{d}-d_{o}\right) \rightarrow_{d} \quad N(0,1 / 4) \quad \text { as } n \rightarrow \infty,
$$

where $d_{o}$ is the true value of $d$, with the only additional requirement that $m \rightarrow \infty$ slower than n. ${ }^{12}$ Robinson (1995a) showed that m must be smaller than $\mathrm{n} / 2$ to avoid aliasing effects. A multivariate extension of this estimation procedure can be found in Lobato (1999). There also exist other semiparametric procedures for estimating the fractional differencing parameter, for example, the log-periodogram regression estimator (LPE), initially proposed by Geweke and Porter-Hudak (1983) and modified later by Künsch (1986) and Robinson (1995b), and the averaged periodogram estimator (APE) of Robinson (1994b). However, we have chosen to use here the local Whittle approach, primarily because of its computational simplicity; in particular, this method (unlike LPE and APE) does not require either additional user-chosen numbers in the estimation, or the Gaussianity assumption in order to obtain an asymptotic normal distribution, being more efficient than LPE.

\section{(Insert Figure 3 about here)}

Figure 3 reports the results based on Robinson (1995a), i.e., $\hat{d}$ given by (15) for a range of values of $\mathrm{m}$ from 1 to $\mathrm{n} / 2{ }^{13,14}$ It also displays the $95 \%$ confidence intervals corresponding to the $\mathrm{I}(0)$ hypothesis for all series and the unit root for the price/dividend ratio. We see that, for inflation and the real risk-free rate, some estimates are within the $\mathrm{I}(0)$ interval, especially if $\mathrm{m}$ is small; however, for most values of $\mathrm{m}$, they are not. For real stock returns and the equity premium almost all values are within the confidence intervals, but not so for the price/dividend ratio. Also, for the latter series, the values are lower than those within the unit root interval, clearly suggesting that $d$ is greater than 0 but smaller than 1 . Therefore, the findings are the 
same as with the parametric procedure, namely there is strong evidence in favour of $\mathrm{I}(0)$ stationarity for real stock returns and the equity premium, some evidence of long memory for inflation and the real risk-free rate, and strong evidence of fractional integration for the price/dividend ratio.

The above approach to investigating the long-run behaviour of a time series consists in testing a parametric model for the series and estimating a semiparametric one, relying on the long run-implications of the estimated models. The advantage of the first procedure is the precision gained by providing all the information about the series through the parameter estimates. A drawback is that these estimates are sensitive to the class of models considered, and may be misleading because of misspecification. It is well known that the issue of misspecification can never be settled conclusively in the case of parametric (or even semiparametric) models. However, the problem can be partly addressed by considering a larger class of models. This is the approach used in what follows, where we employ another version of the tests of Robinson (1994a) that enables us simultaneously to consider roots at zero and the cyclical frequencies. $^{15}$

For this purpose, let us consider now the model given by (3) and (4), with $\rho(L ; \theta)$ as in (8) and $z_{t}=(1, t)^{T}$. Thus, under $H_{o}(6)$, the model becomes:

$$
\begin{gathered}
y_{t}=\beta_{0}+\beta_{1} t+x_{t}, \quad t=1,2, \ldots \\
(1-L)^{d_{1}}\left(1-2 \cos w L+L^{2}\right)^{d_{2}} x_{t}=u_{t}, \quad t=1,2, \ldots,
\end{gathered}
$$

and, if $\mathrm{d}_{2}=0$, the model reduces to the case previously studied of long memory exclusively at the long-run or zero frequency. We assume that $\mathrm{w}=\mathrm{w}_{\mathrm{r}}=2 \pi \mathrm{j} / \mathrm{n}, \mathrm{j}=\mathrm{n} / \mathrm{r}$, and $\mathrm{r}$ indicating the number of time periods per cycle.

\section{(Insert Table 3 about here)}

We first computed the statistic $\hat{R}$ given by (11) for values of $\mathrm{d}_{1}$ and $\mathrm{d}_{2}=-0.50,(0.10)$, 2 , and $\mathrm{r}=2, \ldots, \mathrm{n} / 2,{ }^{16}$ assuming that $\mathrm{u}_{\mathrm{t}}$ is white noise. For brevity, we do not report the results 
for all statistics. In brief, the null hypothesis (6) was rejected for all values of $d_{1}$ and $d_{2}$ if $r$ was smaller than 4 or higher than 9 , implying that, if a cyclical component is present, its periodicity is constrained to be between these two years. This is consistent with the empirical finding in Canova (1998), Burnside (1998), King and Rebelo (1999) and others that cycles have a periodicity between five and ten years. We report in Table 3 the non-rejection cases at the 5\% level only for the case of an intercept and $r=6$. The results for the case of a linear time trend were very similar, and the coefficient corresponding to the linear time trend was found to be insignificantly different from zero in virtually all cases. Note that the test statistic is obtained from the null differenced model, which is assumed to be $I(0)$, and therefore standard t-tests apply. Further, we focus on $r=6$ since the non-rejection values with $r=4,5,7,8$ and 9 formed a proper subset of those non-rejections obtained with $r=6$. We see that for inflation and the real risk-free rate the non-rejection values oscillate between 0.10 and 0.40 for $d_{1}$, and between 0 and 0.3 for $d_{2}$. They are slightly smaller for $d_{2}$ in the case of stock returns and the equity premium, in some cases even being negative. Finally, for the price/dividend ratio, the values of $d_{1}$ range between 0.5 and 1 , while $d_{2}$ seems to be constrained between 0 and $0.5 .^{17}$

\section{(Insert Figure 4 about here)}

In order to have a more precise view about the non-rejection values of $d_{1}$ and $d_{2}$, we recomputed the tests but this time for a shorter grid, with $d_{1}, d_{2}=-0.25,(0.01), 2$. Figure 4 displays the regions of $\left(d_{1}, d_{2}\right)$ values where $H_{o}$ cannot be rejected at the $5 \%$ level. Essentially, the series can be grouped into three categories: inflation and the real risk-free rate; real stock returns and the equity premium; finally, the price/dividend ratio. Starting with the first group (inflation and the real risk-free rate), we observe that the values of $d_{1}$ range between 0.1 and 0.5 while $d_{2}$ seems to lie between 0 and 0.3 . Thus, there appears to be a slightly higher degree of integration at the long-run or zero frequency compared to the cyclical one. For real stock returns and equity premium, the values of both orders of integration oscillate around 0 . Finally, 
for the price/dividend ratio the values of $d_{1}$ range between 0.5 and 1 , while $d_{2}$ is between 0 and 0.5 , implying nonstationarity with respect to the zero frequency but stationarity with respect to the cyclical component, and mean reversion with respect to both. Consequently, shocks to the latter series will disappear in the long run, with those affecting the cyclical part tending to disappear faster than those affecting its long-run or trending behaviour. This procedure was also applied in the context of autocorrelated (AR(1) and $\mathrm{AR}(2))$ disturbances and the results did not substantially differ from those reported here based on white noise $u_{t}$. In the AR(1) case, the AR parameter was not significantly different from zero for most series. The only exception was the price/dividend ratio, for which values of $d_{1}$ close to zero are obtained for an AR parameter close to one, suggesting once more that the order of integration at the zero frequency and the AR parameter are in competition. When using $\mathrm{AR}(2)$ disturbances the results were again very similar, though with larger regions for the $\left(\mathrm{d}_{1}, \mathrm{~d}_{2}\right)$ - non-rejection values.

\section{Forecasting and comparisons with other models}

In this section, we try first to determine the best model specification for each time series. Then, we compare the selected models with other approaches based on $\mathrm{I}(0)$ and $\mathrm{I}(1)$ hypotheses.

Given the lack of efficient procedures for estimating the parameters of the model given by (16) and (17), we have decided to use the following strategy: first, we recompute the values of the test statistic for $\mathrm{d}_{1}, \mathrm{~d}_{2}=-0.50,(0.01), 2$ and $\mathrm{r}=2, \ldots, \mathrm{n} / 2$, for the three cases of no regressors, an intercept and an intercept with a linear time trend. Then, we discriminate between these three cases according to the t-values of the estimated coefficients in (16), and choose the values of $d_{10}, d_{2 o}$ and $r$ which produce the lowest statistic in absolute value. ${ }^{18}$ The selected model for each time series is reported in the second column in Table 4. We find that, for the inflation rate and the real risk-free rate, both orders of integration are between 0.10 and 0.30 , the order of integration at zero being slightly higher than the cyclical one; for real stock 
returns and the equity premium, the values of the d's are close to zero, being slightly negative for the zero frequency; finally, the price-dividend ratio appears to be nonstationary at the longrun frequency $\left(d_{1}=0.68\right)$, and stationary with $d_{2}$ close to zero for the cyclical component. Note that in this case all models are based on white noise disturbances, the reason being that, as mentioned in the previous section, the inclusion of autocorrelated disturbances did not alter the conclusions except for the price/dividend ratio - for this series the associated AR coefficient was very close to one, thus making the estimate of $d_{1}$ invalid. Moreover, the cyclical fractional polynomial can be considered as an alternative to the ARMA specification when describing the short-run dynamics of the series.

\section{(Insert Table 4 about here)}

The third column of the table reports the selected models taking into account only the component affecting the long run or zero frequency, while the fourth refers to the case of integer differentiation with respect to such a frequency. In both cases, we model the cyclical structure using ARMA specifications. Starting with the case of fractional integration, we observe that the highest degree of integration is obtained for the price/dividend ratio $(d=0.73)$, followed by inflation $(d=0.19)$. For the remaining three series, the values are practically zero ( 0.04 for the real risk-free rate; 0.01 for real stock returns, and -0.04 for the equity premium). Here we have followed the same strategy as in the fractional cyclical case, i.e., testing sequentially for a grid of values of $\mathrm{d}_{1}$, and choosing the value that produces the lowest statistic in absolute value. Imposing integer orders of integration, for the first four variables, we use $d=$ 0 while for the price-dividend ratio we try both $d=0$ and 1 . For the short-run components we use $\operatorname{ARMA}(\mathrm{p}, \mathrm{q})$ models, with $\mathrm{p}, \mathrm{q} \leq 3$, and choose the best model specification using both LR tests and likelihood criteria (AIC, BIC). ${ }^{19,20}$ We see that, for most of the series, the short-run structure can be described by simple MA models, the only exceptions being the real risk-free rate where an $\operatorname{AR}(1)$ process is imposed, and the inflation rate $(\operatorname{ARMA}(2,1))$. 
Next, we compare the various models in terms of their forecasting performance. The accuracy of different forecasting methods is a topic of continuing interest and research (see, e.g., Makridakis et al., 1984, for a study on the forecasting accuracy of major forecasting models, and Makridakis and Hibon, 2000, for a summary and review of forecasting competition). Standard measures of forecast accuracy are the following: Theil's U, the mean absolute percentage error (MAPE), the mean-squared error (MSE), the root-mean-squared error (RMSE), the root-mean-percentage-squared error (RMPSE) and mean absolute deviation (MAD) (Witt and Witt, 1992). Let $\mathrm{y}_{\mathrm{t}}$ be the actual value in period $t ; f_{t}$ the forecast value in period $\mathrm{t}$, and $\mathrm{n}$ the number of periods used in the calculation. Then:

a) Theil's $\mathrm{U}: \frac{\sqrt{\sum\left(y_{t}-f_{f}\right)^{2}}}{\sqrt{\sum\left(x_{t}-x_{t-1}\right)^{2}}}$;

b) Mean absolute percentage error (MAPE): $\frac{\sum\left|\left(x_{t}-f_{t}\right) / x_{t}\right|}{n}$;

c) Mean squared error (MSE): $\frac{\sum\left(x_{t}-f_{t}\right)^{2}}{n}$;

d) Root-mean-percentage-squared error (RMSP): $\sqrt{\frac{\sum\left(x_{t}-f_{t}\right)^{2} / f_{t}}{n}}$;

e) Root-mean-squared error (RMSE): $\sqrt{\frac{\sum\left(x_{t}-f_{t}\right)^{2}}{n}}$;

f) Mean absolute deviation (MAD): $\frac{\sum\left|x_{t}-f_{t}\right|}{n}$.

The first type of evaluation criteria measures the spread or dispersion of the forecast value from its mean. The MAD belongs to this category. It measures the magnitude of the forecast errors. Its principal advantages are the ease of interpretation and the fact that each error term is assigned the same weight. However, by using the absolute value of the error term, it ignores the importance of over- or under-estimation. 
The second type of accuracy measure is based on the forecast error, which is the difference between the observation, $\mathrm{x}_{\mathrm{t}}$, and the forecast, $\mathrm{f}_{\mathrm{t}}$. This category includes MSE, RMSE and RMSPE. MSE is simply the average of squared errors for all forecasts. It is suitable when more weight is to be given to big errors, but it has the drawback of being overly sensitive to a single large error. Further, just like MAD, it is not informative about whether a model is overor under-estimating compared to the true values. RMSE is the square root of MSE and is used to preserve units. RMSPE differs from RMSE in that it evaluates the magnitude of the error by comparing it with the average size of the variable of interest. The main limitation of all these statistics is that they are absolute measures for a specific series, and hence do not allow comparisons across different time series and for different time intervals. By contrast, this is possible using a third type of accuracy measure, such as MAPE, which is based on the relative or percentage error. This is particularly useful when the units of measurement of $\mathrm{x}$ are relatively large. However, MAPE also fails to take over- or under-estimation into consideration.

Unlike the measures mentioned above, Theil's $U$ is a relative measure, allowing comparisons with the naïve $\left(\mathrm{x}_{\mathrm{t}}=\mathrm{x}_{\mathrm{t}-1}\right)$ or random walk model, where a $\mathrm{U}=1$ indicates that the naïve method is as good as the forecasting technique, whilst $U<1$ means that the chosen forecasting method outperforms the naïve model. The smaller the U-statistic, the better the performance of the forecasting technique relative to the naïve alternative. However, despite some attractive properties, the U-statistic has the disadvantage of not being as easily interpretable as MAPE; further, it does not have an upper bound, and therefore is not robust to large values.

The three selected time series models (fractional and cyclical differencing, FCD; fractional differencing, FD; and integer differencing, ID) for each of the series were used to generate the 5-year-ahead out-of-sample forecasts. Each forecast value was calculated and 
compared with the actual value of the series. Then, the above six criteria were used to rank the three forecasting models for each series. The ranking in terms of forecasting performance is given in Table 5. We observe that for inflation and the real risk-free rate the FCD model outperforms FD and ID according to all the criteria. For real stock returns and the equity premium, the ID specification seems to be the most adequate, while for the price/dividend ratio the results are mixed. Therefore, on the basis of the MAPE, MSE, RMSP and RMSE criteria, the fractional and cyclical (FCD) model emerges as the best specification, while the other two criteria, MAD and Theil's U, suggest that the simple fractional model (with $d=0.73$ ) is the most adequate one.

\section{(Insert Table 5 about here)}

In Table 6 we focus on the forecasts for inflation and the price/dividend ratio over a longer time-horizon. We consider the forecasting performance of the three types of models discussed above (FCD, FD and ID) over the period 1979 - 1993, based on specifying and estimating the models over the time period 1871 - 1978. The new selected models are displayed in Table 6 and we observe that they are very similar to those reported in Table 4.

\section{(Insert Tables 6 and 7 about here)}

In Table 7 we concentrate on the MSE forecasts for the two series, using the time horizons $h=1,3,6,9,12$ and 15 . We observe that for the two series in many cases the lowest MSEs are obtained with the fractional cyclical models. The MSE measure used for comparing the relative forecasting performance of our models is a purely descriptive device. There exist several statistical tests for comparing different forecasting models. One of these tests, widely employed in the time series literature, is the asymptotic test for a zero expected loss differential of Diebold and Mariano (1995). ${ }^{21}$ The loss differential is defined as

$$
d_{t}=g\left(e_{i t \mid t-h}\right)-g\left(e_{j t \mid t-h}\right),
$$


where $g\left(e_{i t \mid t-h}\right)$ is the loss function, and $e_{i t \mid t-h}$ is the corresponding h-step ahead forecast error for the model i, $e_{i t \mid t-h}=y_{t}-\hat{y}_{i t \mid t-h}$. Given a covariance stationary sample

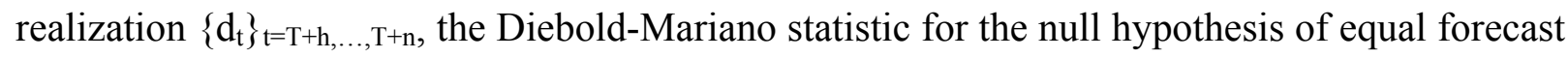
accuracy (i.e., $\left.E\left(d_{t}=0\right)\right)$ is given by:

$$
\frac{\bar{d}}{\sqrt{\hat{V}(\bar{d})}}
$$

where $\bar{d}$ is the sample mean loss differential,

$$
\bar{d}=\frac{1}{n-h+1} \sum_{t=T+h}^{t=T+n} d_{t}
$$

and where $\hat{V}(\bar{d})$ is a consistent estimate of the asymptotic variance of $\bar{d}$, which is computed as an unweighted sum of the sample autocovariances, that is,

$$
\hat{V}(\bar{d})=\frac{1}{n-h+1}\left(\hat{\gamma}_{0}+2 \sum_{k=0}^{h-1} \hat{\gamma}_{k}\right),
$$

where

$$
\hat{\gamma}_{k}=\frac{1}{n-h+1} \sum_{t=T+h+k}^{T+n}\left(d_{t}-\bar{d}\right)\left(d_{t-k}-\bar{d}\right) .
$$

Using the Diebold-Mariano statistic, we further evaluate the relative forecast performance of the different models by making pairwise comparisons. We display with an asterisk, in Table 7, for each prediction, the rejections of the null hypothesis that the forecast performance of model $\mathrm{i}$ and $\mathrm{j}$ is equal in favour of the one-sided alternative that model i's performance is superior at the $5 \%$ significance level. ${ }^{22}$ Given the fact that we have three potential models for each prediction and we make pairwise comparisons, we only display with an asterisk the model that is preferred to the other two, leaving out those cases where there is no consistency about the preferred model. We note here that over long horizons the fractional cyclical model produces for both series significantly superior forecasts. 


\section{Conclusions}

In this paper we have examined the time series behaviour of the US stock market over the time period 1871 - 1993 by means of new statistical techniques based on long memory processes. Specifically, we have used a procedure due to Robinson (1994a) that has enabled us to test for unit roots with integer or fractional orders of integration, not only at zero but also at the cyclical frequencies. These tests have standard null and local limit distributions and can easily be applied to raw time series. ${ }^{23}$

Initially, we focused only on the long-run or zero frequency, applying a suitable version of Robinson's (1994a) parametric tests along with a semiparametric estimation procedure. We used these methods because of the distinguishing features that make them particularly relevant in the context of financial time series. Specifically, they do not require Gaussianity (which is an assumption that is not satisfied by most financial series), but only a moment condition of order two. Additionally, they have standard null limit distributions, which is another advantage of these tests compared to other procedures based on AR alternatives. The order of integration estimated using these methods varies considerably, but nonstationarity is found only in the case of the price/dividend ratio.

However, the non-rejection values obtained at the zero frequency could be partly due to the fact that attention has not been paid to other possible (cyclical) frequencies of the process. Thus, we adopted a method suitable for simultaneously testing for the presence of roots at the zero and the cyclical frequencies, as in Robinson (1994a). For the latter frequencies, the model is based on Gegenbauer processes. The results suggest that the periodicity of the series ranges between 5 and 10 years, which is consistent with most of the empirical literature on cycles finding a periodicity of about six years (see, e.g., Baxter and King, 1999, Canova, 1998, and King and Rebelo, 1999). Further, the series can be grouped into three different categories: inflation and the real risk-free rate, with the order of integration at the zero frequency 
fluctuating between 0 and 0.5 and $\mathrm{d}_{2}$ (cyclical integration) between 0 and 0.3 ; real stock returns and the equity premium, with both orders of integration fluctuating around 0 ; and finally, the price/dividend ratio, with $d_{1}$ ranging between 0.5 and 1 and $d_{2}$ between 0 and 0.5 . Thus, we found evidence of stationary long memory with respect to both components for inflation and the real risk-free rate; $\mathrm{I}(0)$ stationarity for stock returns and the equity premium; and nonstationary long memory at the zero frequency but stationarity at the cyclical component for the price/dividend ratio. Finally, the fact that all orders of integration are smaller than 1 suggests that mean reversion takes place with respect to both components for all series, though the rate of adjustment varies across them.

A criticism that could be made of this type of model for the cyclical component is that, unlike seasonal cycles, business cycles are typically weak and irregular and are spread evenly over a range of frequencies rather than peaking at a specific value. A strong counterargument is that, in spite of the fixed frequencies used in this specification, flexibility can be achieved through the first differenced polynomial, the ARMA components and the error term. In fact, Bierens (2001) uses a model of this kind (with $d_{2}=1$ ) to test for the presence of business cycles in the annual change of monthly unemployment in the UK. Our analysis also yields clear-cut results, which are consistent with earlier findings on the periodicity of cycles.

The selected models for each time series were then compared with other approaches based on fractional and integer differentiation for the zero frequency. Six forecasting criteria were employed and the results showed that the fractional cyclical model outperforms the others in a number of cases.

It would also be worthwhile to obtain point estimates of the fractional differencing parameters in this context of trends and cyclical models. For the trending component the literature is vast (see, e.g., Fox and Taqqu, 1986; Dahlhaus, 1989; Sowell, 1992; Tanaka, 1999, etc.). For the cyclical part, there are fewer contributions such as Arteche and Robinson (2000) 
and Arteche (2002). However, the goal of this paper is to show that a model with fractional orders of integration at both the zero and the cyclical frequencies can be a credible alternative to the conventional ARIMA (ARFIMA) specifications. In fact, our approach produces unambiguous results, with the periodicity ranging between 4 and 10 years and most of the orders of integration within the intervals $(0,0.5)$ and $(0.5,1)$ depending on the series and the component under study.

Further research could be carried out using this framework. For instance, the tests of Robinson (1994a) can be extended to allow for more than one cyclical component underlying the process. The existence of multiple cycles in financial series has not yet been examined empirically, and might be of interest in the context of various latent variates. Further, daily data could also be used to examine intraday periodicity, e.g. in the volatility of asset returns. As an alternative to the cyclical fractional approach, Andersen and Bollerslev (1997) modelled periodicity in returns by means of deterministic weights. The inclusion of deterministic components is possible in Robinson's (1994a) set-up, and its significance can be tested by means of a joint test of the deterministic regressors and of the order of integration. The univariate nature of the present study is also a limitation in terms of theorising, policy-making or forecasting. Theoretical models and policy-making involve relationships between many variables, and forecast performance can be improved through the use of many variables (e.g., factor-based forecasts based on hundreds of time series beat univariate forecasts, as shown, e.g., in Stock and Watson, 2002). However, the univariate approach taken in the present paper is useful, as it enables one to decompose the series into a long-run and a cyclical component. Moreover, theoretical econometric models for both long-run and cyclical fractional structures in a multivariate framework are not yet available. In this respect, the present study can be seen as a preliminary step in the analysis of financial data from a different time series perspective. Of particular interest in future work would be a more extensive study of the out-of-sample 
forecasting performance of our preferred model. In order to increase the number of out-ofsample observations and gain power, a rolling design could be used. Alternatively, larger samples could be obtained using higher frequency data, such as quarterly series. Data mining is an additional relevant issue worth exploring. 


\section{Footnotes}

1. Note that, for example, most of the "classical" unit root tests (i.e., Dickey and Fuller, 1979; Kwiatkowski et al., 1992; etc.) are non-standard, in the sense that the critical values have to be calculated numerically on a case-by-case simulation approach.

2. Note that, although the model presented in Section 1 only has a single innovation term, this is obtained by combining two fractional processes, one for the long run and the other for the cyclical structure.

3. For the purposes of the present paper, we define an $\mathrm{I}(0)$ process as a covariance stationary process with spectral density function that is positive and finite at any frequency.

4. Ciozcek-Georges and Mandelbrot (1995), Taqqu et al. (1997), Chambers (1998) and Lippi and Zaffaroni (1999) also use aggregation to motivate long memory processes.

5. Note that a truncation is also required in case of the zero frequency. For an alternative definition of fractional integration at the zero frequency (the type I class), see Marinucci and Robinson (1999).

6. Unit root cycles were also examined by Ahtola and Tiao (1987), Chan and Wei (1988) and Gregoir (1999a, b).

7. These conditions are very mild and concern technical assumptions to be satisfied by $\psi_{1}(\lambda)$ and $\psi_{2}(\lambda)$

8. In other words, if the tests are implemented against local departures of the form: $H_{a}: \theta=$ $\delta \mathrm{n}^{-1 / 2}$, for $\delta \neq 0$, the limit distribution is a $\chi_{2}^{2}(v)$ with a non-centrality parameter $\mathrm{v}$, which is optimal under Gaussianity of $u_{t}$.

9. The confidence intervals were constructed using the following strategy. First, choose a value of $d$ from a grid. Then, form the test statistic testing the null for this value. If the null is rejected at the $95 \%$ level, discard this value of d. Otherwise, keep it. An interval is then obtained after considering all the values of $d$ in the grid. 
10. See Robinson and Iacone (2004) for a recent paper on fractional integration (and cointegration) and deterministic trends.

11. Velasco $(1999 \mathrm{a}, \mathrm{b})$ has recently shown that the fractionally differencing parameter can also be consistently estimated in a semiparametric way in nonstationary contexts by means of tapering. Phillips and Shimotsu (2004) point out that the estimator of Robinson (1995a) is not adequate since it is not asymptotically consistent under certain parameter values. In Phillips and Shimotsu (2005) they propose an exact local Whittle estimator with better statistical properties than Robinson's (1995a). Using that approach, they reached practically identical conclusions to those in Robinson, 1995a.

12. The exact requirement is that $(1 / \mathrm{m})+\left(\left(\mathrm{m}^{1+2 \alpha}(\log \mathrm{m})^{2}\right) /\left(\mathrm{n}^{2 \alpha}\right)\right) \rightarrow 0$ as $\mathrm{n} \rightarrow \infty$, where $\alpha$ is determined by the smoothness of the spectral density of the short-run component. In the event of a stationary and invertible ARMA, $\alpha$ may be set equal to 2 and the condition is $(1 / \mathrm{m})+$ $\left(\left(\mathrm{m}^{5}(\log \mathrm{m})^{2}\right) /\left(\mathrm{n}^{4}\right)\right) \rightarrow 0$ as $\mathrm{n} \rightarrow \infty$.

13. In the case of the price/dividend ratio, and in order to ensure stationarity, the estimates were based on the first differenced data, then adding one to the estimated values of $d$ to get the proper orders of integration.

14. Some methods to calculate the optimal bandwidth numbers have been examined in Delgado and Robinson (1996) and Robinson and Henry (1996). However, in the case of the Whittle estimator, the use of optimal values has not been theoretically justified. Other authors, such as Lobato and Savin (1998) use an interval of values for m, but we have preferred to report the results for the whole range of values of $\mathrm{m}$.

15. On the other hand, it is also important to note that if cyclical components are present in the series and we do not take them into account, the estimation of $d$ at the zero frequency may create biases in favour of long memory. (See, e.g., Montanari, Rosso and Taqqu, 1995, 1996, 1997). 
16. Note that, in the case of $r=1$, the model reduces to the case previously studied of long memory exclusively at the long-run or zero frequency.

17. It should be noted that, although $\mathrm{d}_{2}=0$ cannot be statistically rejected in most cases, in general, it is "less clearly non-rejected" than for positive values of $d_{2}$. (By "less clearly nonrejected" we mean that the value of the test statistic is closer to the critical value. See the results in Table 3).

18. Note that, for each $r$, the values of $d_{1}$ and $d_{2}$ producing the lowest statistic should be an approximation to the maximum likelihood estimates since the procedure employed in the paper is based on the LM principle and uses the Whittle function, which is an approximation to the likelihood function.

19. In the context of fractional differentiation, we discriminate between the white noise and the AR specification by also looking at the significance of the AR parameter: if it is close to 0 or 1 , we choose the white noise model for $u_{t}$. In fact, this is what we have done for the equity premium and the price/dividend ratio. Also, note that for the real risk-free rate, the inclusion of AR disturbances substantially reduces the order of integration at the zero frequency (from 0.25 in the FCD model to 0.04 in FD).

20. It should be noted, however, that the AIC and the BIC are not necessarily the best criteria for applications involving fractional differences, as they concentrate on the short-term forecasting ability of the fitted model and may not give sufficient attention to the long-run properties of the ARFIMA models (see, e.g. Hosking, 1981, 1984). Another recent paper about model selection in the presence of long and short memory processes is Beran et al (1998). They propose versions of the AIC, BIC and the HQ (Hannan and Quinn, 1979) which are suitable for fractional autoregressions, but do not consider MA components.

21. An alternative approach is the bootstrap-based test of Ashley (1998) though this method is computationally more intensive. 
22. Note that, since the forecasts are measured by MSE, the quadratic loss function is $g\left(e_{i t \mid t-h}\right)=e_{i t \mid t-h}^{2}$

23. A diskette containing the FORTRAN programs is available from the authors upon request. 


\section{References}

Ahtola, J.. and Tiao, G.C., 1987, Distributions of least squares estimators of autoregressive parameters for a process with complex roots on the unit circle, Journal of Time Series Analysis 8, 1-14.

Andersen, T.G. and T. Bollerslev, 1997, Heterogeneous information arrivals of return volatility dynamics: increasing the long run in high frequency returns, Journal of Finance 52, 975-1006.

Arteche, J., 2002, Semiparametric robust tests on seasonal and cyclical long memory series, Journal of Time Series Analysis 23, 1-35.

Arteche, J. and P.M. Robinson, 2000, Semiparametric inference in seasonal and cyclical long memory processes, Journal of Time Series Analysis 21, 1-25.

Ashley, R., 1998, A new technique for postsample model selection and validation, Journal of Economics Dynamics and Control 22, 647-665.

Backus, D. and S. Zin, 1993, Long memory inflation uncertainty: Evidence of term structure of interest rate, Journal of Money, Credit and Banking 25, 687-700.

Baillie, R.T., 1996, Long memory processes and fractional integration in econometrics, Journal of Econometrics 73, 5-59.

Baillie, R.T., C-F. Chung and M.A. Tieslau, 1996, Analysing inflation by the fractionally integrated ARFIMA-GARCH model, Journal of Applied Econometrics 11, 23-40.

Baxter, M. and R.G. King, 1999, Measuring business cycles approximate band-pass filters for economic time series, The Review of Economics and Statistics 81, 575-593.

Beaudry P. and G. Koop, 1993, Do recessions permanently change output?, Journal of Monetary Economics 31, 149-163.

Beran, J., Bhansali, R.J. and Ocker, D., 1998, On unified model selection for stationary and nonstationary short- and long-memory autoregressive processes, Biometrika 85, 921-934. 
Bhargava, A., 1986, On the theory of testing unit roots in observed time series, Review of Economic Studies 53, 369-384.

Bierens, H.J., 2001, Complex unit roots and business cycles. Are they real?, Econometric Theory $17,962-983$.

Burnside, A.C., 1998, Detrending and business cycle facts. A comment, Journal of Monetary Economics 41, 513-532.

Candelon, B. and L. A. Gil-Alana, 2004, Fractional integration and business cycle features, Empirical Economics 29, 1-17.

Canova, F., 1998, Detrending and business cycle facts. A user's guide, Journal of Monetary Economics 41, 533-540.

Caporale, G.M. and L.A. Gil-Alana, 2002, Fractional integration and mean reversion in stock prices, Quarterly Review of Economics and Finance 42, 599-609.

Cecchetti, S.G., Lam, P.-S. and N.C. Mark, 1990, Mean reversion in equilibrium asset prices, American Economic Review 80, 398-418.

Chambers, M., 1998, Long memory and aggregation in macroeconomic time series, International Economic Review 39, 1053-1072.

Chan, Y. and C.Z. Wei, 1988, Limiting distributions of least squares estimates of unstable autoregressive processes, Annals of Statistics 16, 367-401.

Cioczek-Georges, R. and B.B. Mandelbrot, 1995, A class of micropulses and anti-persistent fractional Brownian motion, Stochastic Processes and Their Applications 60, 1-18.

Dahlhaus, R., 1989, Efficient parameter estimation for self-similar process, Annals of Statistics $17,1749-1766$.

Delgado, M.A. and P.M. Robinson, 1996, Optimal spectral bandwidth for long memory. Statistica Seneca, 6, 97-112. 
Dickey, D. A. and W. A. Fuller, 1979, Distribution of the estimators for autoregressive time series with a unit root, Journal of the American Statistical Association 74, 427-431.

Dickey, D. A., D. P. Hasza and W. A. Fuller, 1984, Testing for unit roots in seasonal time series, Journal of the American Statistical Association 79, 355-367.

Diebold, F.X. and A. Inoue, 2001, Long memory and regime switching, Journal of Econometrics 105, 131-159.

Diebold, F.X. and R.S. Mariano, 1995, Comparing predictive accuracy, Journal of Business, Economics and Statistics 13, 253-263.

Diebold, F.X. and G.D. Rudebusch, 1989, Long memory and persistence in aggregate output, Journal of Monetary Economics 24, 189-209.

Ferrara, L. and D. Guegan, 2001, Forecasting with k-factor Gegenbauer processes: Theory and applications, Journal of Forecasting 20, 581-601.

Fiorentini, G. and E. Sentana, 1998, Conditional means of time series processes and time series processes for conditional means, International Economic Review 39, 1101-1118.

Forbes, W.P., 1996, Picking winners? A survey of the mean reversion and overreaction of stock price literature, Journal of Economic Surveys 10, 123-158.

Fox, R. and M.S. Taqqu, 1986, Large-sample properties of parameter estimates for strongly dependent stationary Gaussian time series, Annals of Statistics 14, 517-532.

Geweke, J. and S. Porter-Hudak, 1983, The estimation and application of long memory time series models, Journal of Time Series Analysis 4, 221-238.

Gil-Alana, L.A., 2001, Testing stochastic cycles in macroeconomic time seris, Journal of Time Series Analysis 22, 411-430.

Gil-Alana, L.A. and P.M. Robinson, 1997, Testing of unit roots and other nonstationary hypotheses in macroeconomic time series, Journal of Econometrics 80, 241-268. 
Gil-Alana, L.A. and P.M. Robinson , 2001, Testing seasonal fractional integration in the UK and Japanese consumption and income, Journal of Applied Econometrics 16, 95-114.

Giraitis, L. and P. Leipus, 1995, A generalized fractionally differencing approach in long memory modelling, Lithuanian Mathematical Journal 35, 65-81.

Granger, C.W.J., 1980, Long memory relationships and the aggregation of dynamic models, Journal of Econometrics 14, 227-238.

Granger, C.W.J., 1981, Some properties of time series data and their use in econometric model specification, Journal of Econometrics 16, 121-130.

Gray, H.L., Yhang, N. and Woodward, W.A., 1989, On generalized fractional processes, Journal of Time Series Analysis 10, 233-257.

Gray, H.L., Yhang, N. and Woodward, W.A., 1994, On generalized fractional processes. A correction, Journal of Time Series Analysis 15, 561-562.

Gregoir, S., 1999a, Multivariate time series with various hidden unit roots. Part I. Integral operator algebra and representation theory, Econometric Theory 15, 435-468.

Gregoir, S., 1999b, Multivariate time series with various hidden unit roots. Part II. Estimation and testing, Econometric Theory 15, 469-518.

Hannan, E.J. and Quinn, B.G., 1979, The determination of the order of an autoregression, Journal of the Royal Statistical Society, Series B. 41, 190-195.

Harvey, A., 1985, Trends and cycles in macroeconomic time series, Journal of Business and Economics Statistics 3, 216-227.

Hassler, U. and J. Wolters, 1995, Long memory in inflation rates. International evidence, Journal of Business and Economic Statistics 13, 37-45.

Hosking, J.R.M., 1981, Fractional differencing, Biometrika 68, 168-176.

Hosking, J.R.M., 1984, Modelling persistence in hydrological time series using fractional differencing, Water Resources Research 20, 1898-1908. 
Hyllerberg, S., R.F. Engle, C.W.J. Granger and B.S. Yoo, 1990, Seasonal integration and cointegration, Journal of Econometrics 44, 215-238.

King, R.G. and S.T. Rebelo, 1999, Resucitating real business cycles, in J.B. Taylor and M. Woodford eds., Handbook in Macroeconomics, Vol. 1, 928-1001.

Künsch, H., 1986, Discrimination between monotonic trends and long-range dependence, Journal of Applied Probability 23, 1025-1030.

Kwiatkowski, D., P. C. B. Phillips, P. Schmidt, and Y. Shin, 1992, Testing the null hypothesis of stationarity against the alternative of a unit root, Journal of Econometrics 54, 159-178.

Lee, D.K.C. and P.M. Robinson, 1996, Semiparametric exploration of long memory in stock prices, Journal of Statistical Planning and Inference 50, 155-174.

Lippi, M. and P. Zaffaroni, 1999, Contemporaneous aggregation of linear dynamic models in large economies, Manuscript, Research Department, Bank of Italy.

Lo, A., 1991, Long term memory in stock prices, Econometrica 59, 1279-1313.

Lo, A, and A.C. MacKinlay, 1988, Stock prices do not follow a random walk. Evidence from a simple specification test, Review of Financial Studies 1, 41-66.

Lobato, I., 1999, A semiparametric two-step estimator for a multivariate long memory process, Journal of Econometrics 73, 303-324.

Lobato, I.N. and N.E. Savin, 1998, Real and spurious long memory properties of stock market data. Journal of Business and Economic Statistics, 16, 261-283.

Marinucci, D. and P.M Robinson, 1999, Semiparametric Fractional Cointegration Models, Journal of Statistical Planning and Inference 80, 111-122.

May, C.T., 1999, Non-linear Pricing. Theory and Practise, John Wiley \& Sons Inc. New York. Montanari, A., Rosso, R. and M.S. Taqqu, 1995, A seasonal fractional differenced ARIMA model: An application to the Nile River monthly flows at Aswan, Preprint. 
Montanari, A. Rosso, R. and M.S. Taqqu, 1996, Some long run properties of rainfall records in Italy, Journal of Geophysical Resources_Atmosphere 101, 431-438.

Montanari, A., Rosso, R. and M.S. Taqqu, 1997, Fractionally differenced ARIMA models applied to hydrological time series. Identification, estimation and simulation, Water Resources Parke, W.R., 1999, What is fractional integration?, The Review of Economics and Statistics 81, 632-638.

Pesaran, M.H. and S.M Potter, 1997, A floor and ceiling model of US output, Journal of Economics Dynamics and Control 21, 661-695.

Phillips, P.C.B., 1987, Time series regression with a unit root, Econometrica 55, 277-301.

Phillips, P.C.B. and P. Perron, 1988, Testing for a unit root in a time series regression, Biometrika 75, 335-346.

Phillips, P.C.B. and K. Shimotsu, 2004, Local Whittle estimation in nonstationary and unit root cases, Annals of Statistics 32, 656-692.

Phillips, P.C.B. and K: Shimotsu, 2005, Exact local Whittle estimation of fractional integration, forthcoming in Annals of Statistics.

Porter-Hudak, S., 1990, An application of the seasonal fractionally differenced model to the monetary aggregates, Journal of the American Statistical Association 85, 338-344.

Poterba, J. and L. Summers, 1988, Mean reversion in stock returns. Evidence and implications, Journal of Financial Economics 22, 27-60.

Robinson, P.M., 1978, Statistical inference for a random coefficient autoregressive model, Scandinavian Journal of Statistics 5, 163-168.

Robinson, P.M., 1994a, Efficient tests of nonstationary hypotheses, Journal of the American Statistical Association 89, 1420-1437.

Robinson, P.M., 1994b, Semiparametric analysis of long memory time series, Annals of Statistics 22, 515-539. 
Robinson, P.M., 1995a, Gaussian semiparametric estimation of long range dependence, Annals of Statistics 23, 1630-1661.

Robinson, P.M., 1995b, Log-periodogram regression of time series with long range dependence, Annals of Statistics 23, 1048-1072.

Robinson, P.M., 2001, The memory of stochastic volatility models, Journal of Econometrics 101, 195-218.

Robinson, P.M. and M. Henry, 1996, Bandwidth choice in Gaussian semiparametric estimation of long-range dependence. P.M. Robinson and M. Rosenblatt eds. Athens Conference on Applied Probability in Time Series Analysis, Vol.II, New York, 220-232.

Robinson, P.M. and F. Iacone, 2004, Cointegration in fractional systems with deterministic trends, Suntory and Toyota International Centres for Economics and Related Disciplines, LSE, Discussion Paper No. EM/04/476.

Schmidt, P. and P.C.B. Phillips, 1992, LM tests for a unit root in the presence of deterministic trends, Oxford Bulletin of Economics and Statistics 54, 257-287.

Shea, G., 1991, Uncertainty and implied variance bounds of long memory models of the interest rate term structure, Empirical Economics 16, 287-312.

Sowell, F., 1992, Maximum likelihood estimation of stationary univariate fractionally integrated time series models, Journal of Econometrics 53, 165-188.

Stock, J.H. and M.W. Watson, 2002, Macroeconomic forecasting using diffusion indexes, Journal of Business and Economic Statistics 20, 147-162.

Tanaka, K., 1999, The nonstationary fractional unit root, Econometric Theory 15, 549-582.

Taqqu, M.S., W. Willinger and R. Sherman, 1997, Proof of a fundamental result in self-similar traffic modelling, Computer Communication Review 27, 5-23.

Velasco, C., 1999a, Nonstationary log-periodogram regression, Journal of Econometrics 91, 299-323. 
Velasco, C., 1999b, Gaussian semiparametric estimation of nonstationary time series, Journal of Time Series Analysis 20, 87-127.

Witt, S.F. and C.A. Witt, 1995, Modelling and forecasting demand in tourism. San Diego, Academic Press.

Woodward, W.A., Q.C. Cheng and H.L. Ray, 1998, A k-factor Gamma long memory model, Journal of Time Series Analysis 19, 485-504. 


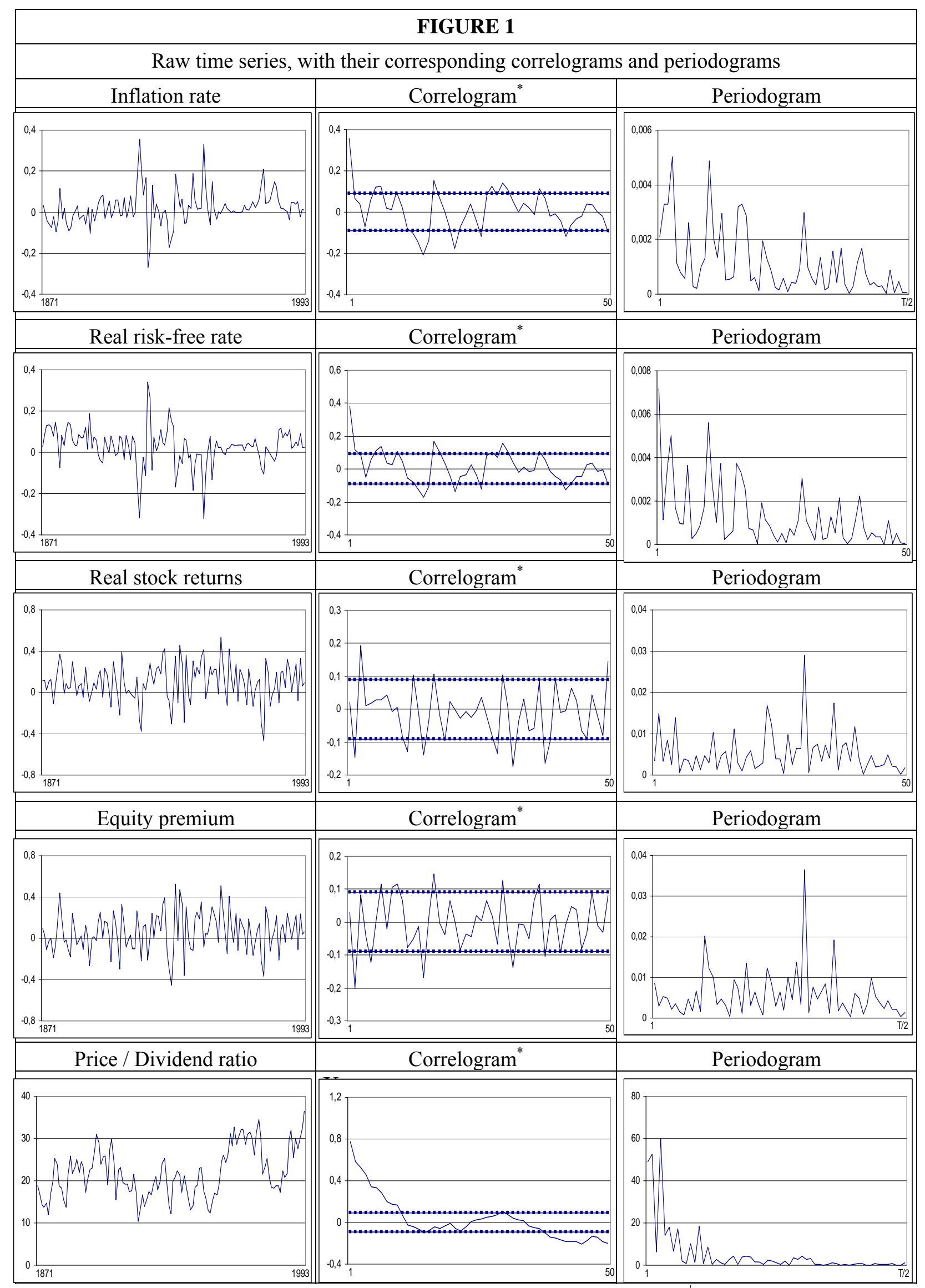

* The large sample standard error under the null hypothesis of no autocorrelation is $1 / \sqrt{ } \mathrm{n}$ or roughly 0.09 for series of the length considered here. 


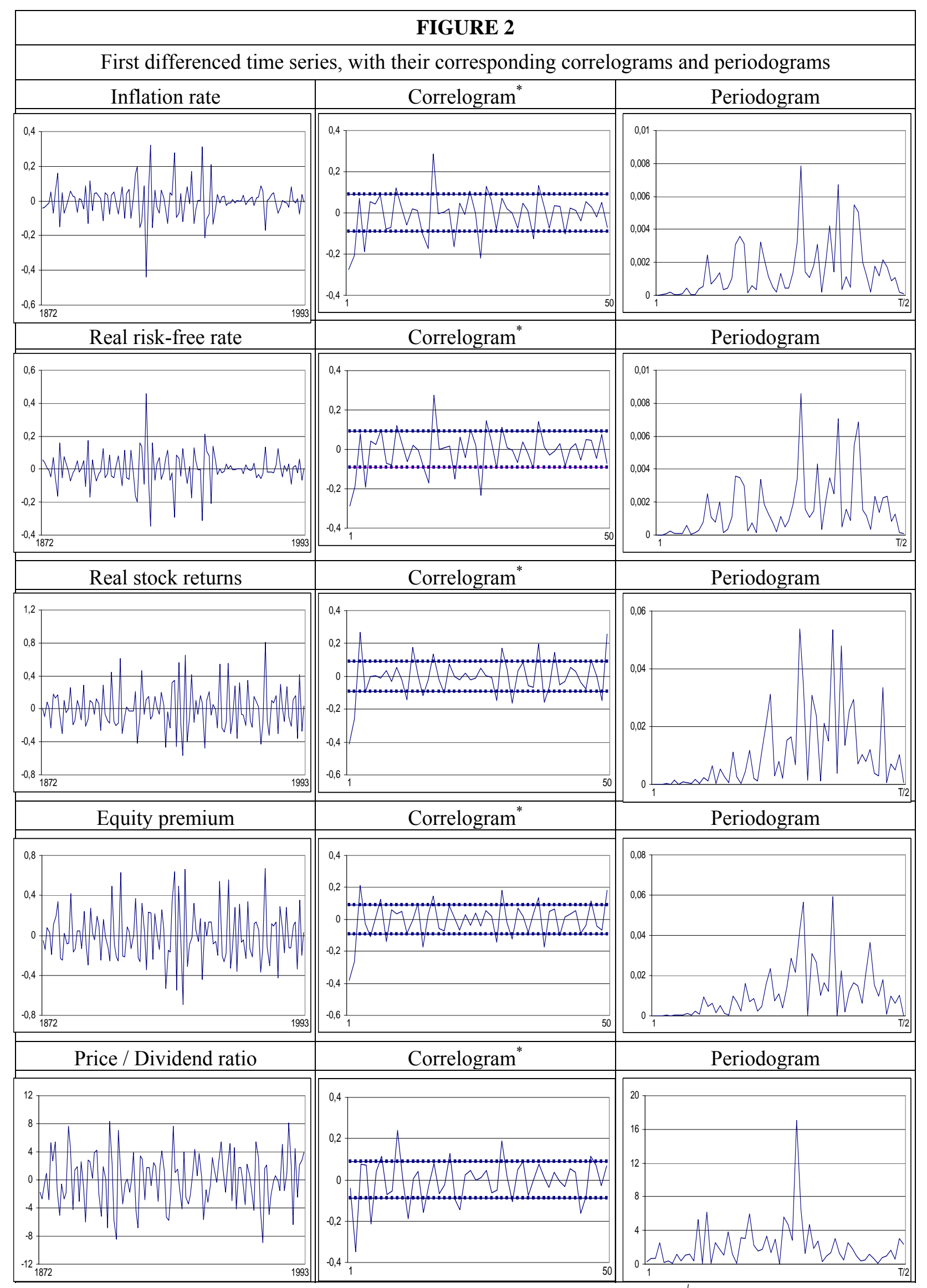

* The large sample standard error under the null hypothesis of no autocorrelation is $1 / \sqrt{ }$ n or roughly 0.09 for series of the length considered here. 


\begin{tabular}{|c|c|c|c|}
\hline \multicolumn{5}{|c|}{ TABLE 1 } \\
\hline \multicolumn{3}{|c|}{ Confidence intervals of the non-rejection values of d using $\hat{R}$ in $(11)$ with $\rho(\mathrm{L} ; \theta)=(1-\mathrm{L})^{\mathrm{d}+\theta}$} \\
\hline Time Series & No regressors & An intercept & A linear trend \\
\hline INFLATION RATE & {$[0.12-0.45]$} & {$[0.13-0.46]$} & {$[0.07-0.44]$} \\
\hline REAL RISK-FREE RATE & {$[0.19-0.49]$} & {$[0.17-0.47]$} & {$[0.15-0.47]$} \\
\hline REAL STOCK RETURN & {$[-0.09-0.14]$} & {$[-0.10-0.13]$} & {$[-0.10-0.13]$} \\
\hline EQUITY PREMIUM & {$[-0.12-0.10]$} & {$[-0.14-0.10]$} & {$[-0.18-0.08]$} \\
\hline PRICE / DIVIDEND RATIO & {$[0.72-1.02]$} & {$[0.58-0.92]$} & {$[0.59-0.92]$} \\
\hline
\end{tabular}

We test the null hypothesis: $d=d_{o}$ in the model $(1-L)^{d} x_{t}=\varepsilon_{t}$.

\begin{tabular}{|c|c|c|c|}
\hline \multicolumn{5}{|c|}{ TABLE 2} \\
\hline \multicolumn{2}{|c|}{ and AR $(1) \mathrm{u}_{\mathrm{t}}$} \\
\hline Confidence intervals of the non-rejection values of $\mathrm{d}$ using $\hat{R}$ in $(11)$ with $\rho(\mathrm{L} ; \theta)=(1-\mathrm{L})^{\mathrm{d}+\theta}$ \\
\hline Time Series & No regressors & An intercept & A linear trend \\
\hline INFLATION RATE & {$[-0.13-0.19]$} & {$[-0.18-0.20]$} & {$[-0.44-0.11]$} \\
\hline REAL RISK-FREE RATE & {$[-0.11-0.33]$} & {$[-0.08-0.28]$} & {$[-0.14-0.27]$} \\
\hline REAL STOCK RETURN & {$[-0.17-0.20]$} & {$[-0.25-0.18]$} & {$[-0.26-0.18]$} \\
\hline EQUITY PREMIUM & {$[-0.22-0.00]$} & {$[-0.30-0.00]$} & {$[-0.41--0.04]$} \\
\hline PRICE / DIVIDEND RATIO & {$[0.24-0.83]$} & {$[0.15-0.58]$} & {$[0.13-0.60]$} \\
\hline
\end{tabular}

We test the null hypothesis: $\mathrm{d}=\mathrm{d}_{\mathrm{o}}$ in the model $(1-\mathrm{L})^{\mathrm{d}} \mathrm{x}_{\mathrm{t}}=\mathrm{u}_{\mathrm{t}} ; \mathrm{u}_{\mathrm{t}}=\tau \mathrm{u}_{\mathrm{t}-1}+\varepsilon_{\mathrm{t}}$ 


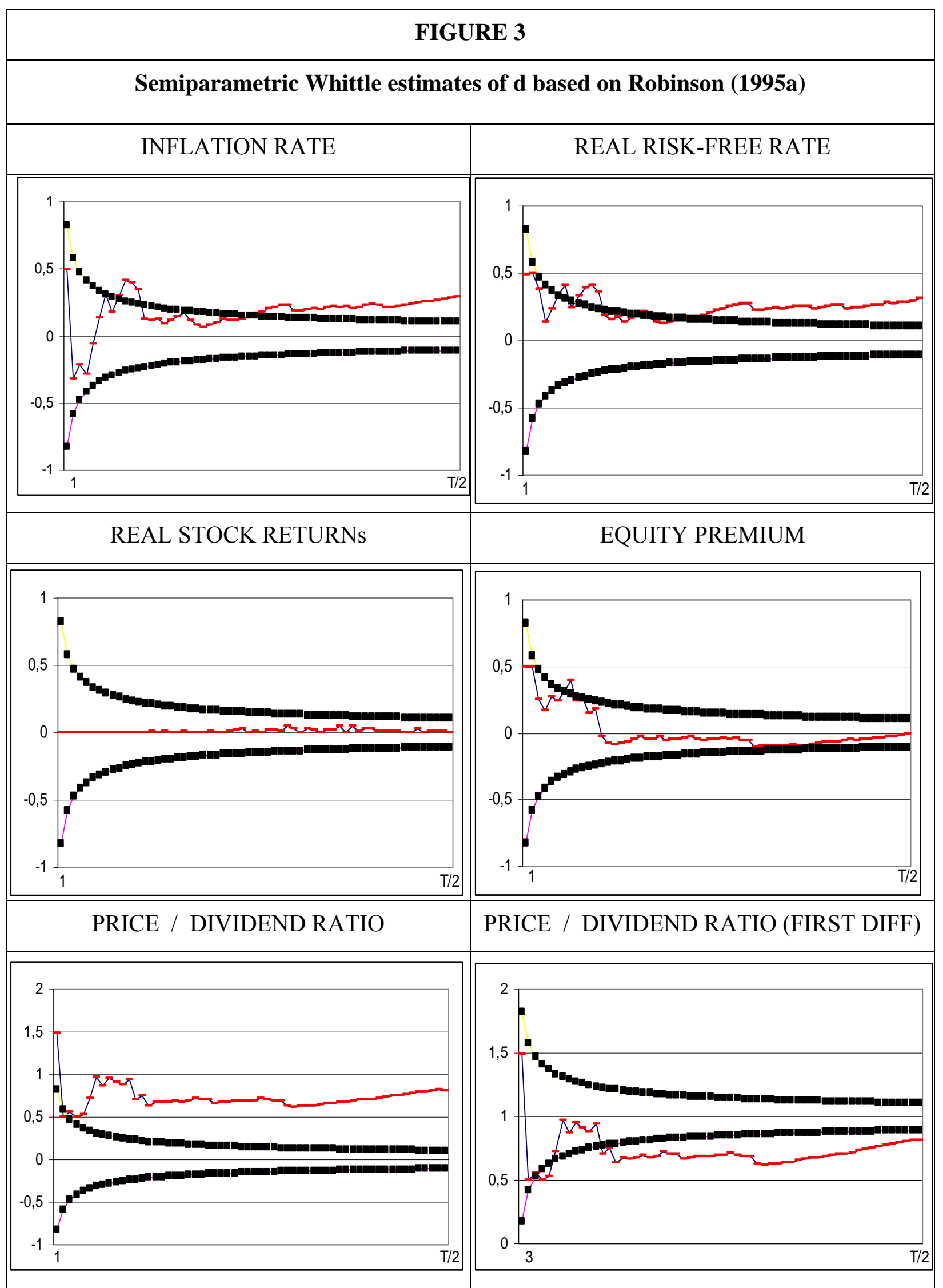

The horizontal axis corresponds to the bandwidth parameter $\mathrm{m}$, whilst the vertical one refers to the order of integration. 
TABLE 3

Testing $\mathrm{H}_{\mathrm{o}}(6)$ in (16), (4) and (8) with $\mathrm{z}_{\mathrm{t}} \equiv 1, \mathrm{w}=\mathrm{w}_{\mathrm{r}}, \mathrm{r}=6$ and white noise $\mathrm{u}_{\mathrm{t}}$

\begin{tabular}{|c|c|c|c|c|c|c|}
\hline $\mathrm{d}_{1}$ & $\mathrm{~d}_{2}$ & INFLATION & RISK RATE & STOCK RT & PREMIUM & PRICE / DIV \\
\hline-0.10 & -0.10 & 39.49 & 51.69 & 4.03 & 4.84 & 236.63 \\
\hline-0.10 & 0.00 & 36.06 & 55.05 & $3.38^{*}$ & $0.69^{*}$ & 254.45 \\
\hline-0.10 & 0.10 & 36.86 & 58.98 & $4.64^{*}$ & $0.90^{*}$ & 265.93 \\
\hline-0.10 & 0.20 & 37.25 & 60.01 & 6.61 & $3.03^{*}$ & 272.99 \\
\hline 0.00 & -0.10 & 28.25 & 30.70 & $0.14^{*}$ & $4.35^{*}$ & 170.35 \\
\hline 0.00 & 0.00 & 16.73 & 24.09 & $0.43^{*}$ & $0.54^{*}$ & 186.83 \\
\hline 0.00 & 0.10 & 13.29 & 23.03 & $2.96^{*}$ & $1.81^{*}$ & 197.19 \\
\hline 0.00 & 0.20 & 12.66 & 22.78 & 6.60 & $5.29^{*}$ & 202.97 \\
\hline 0.10 & -0.10 & 25.25 & 22.51 & $1.32^{*}$ & $5.49^{*}$ & 112.99 \\
\hline 0.10 & 0.00 & 8.42 & 9.72 & $1.95^{*}$ & $2.74^{*}$ & 125.92 \\
\hline 0.10 & 0.10 & $3.04^{*}$ & 6.19 & $5.64^{*}$ & $5.11^{*}$ & 133.05 \\
\hline 0.10 & 0.20 & $2.72^{*}$ & 6.26 & 10.39 & 9.57 & 137.62 \\
\hline 0.10 & 0.30 & $4.70^{*}$ & 7.72 & 15.49 & 14.84 & 141.08 \\
\hline 0.20 & -0.10 & 24.90 & 20.29 & $3.41^{*}$ & 6.91 & 68.85 \\
\hline 0.20 & 0.00 & $5.70^{*}$ & $4.50^{*}$ & $5.18^{*}$ & $5.48^{*}$ & 76.73 \\
\hline 0.20 & 0.10 & $0.20^{*}$ & $0.50^{*}$ & 9.78 & 8.87 & 81.48 \\
\hline 0.20 & 0.20 & $1.09^{*}$ & $1.78^{*}$ & 15.19 & 13.99 & 83.13 \\
\hline 0.20 & 0.30 & $4.84^{*}$ & $5.32^{*}$ & 20.69 & 19.63 & 82.15 \\
\hline 0.30 & -0.10 & 25.10 & 20.09 & $5.89^{*}$ & 8.23 & 38.97 \\
\hline 0.30 & 0.00 & $5.65^{*}$ & $3.62^{*}$ & 8.78 & 8.19 & 41.56 \\
\hline 0.30 & 0.10 & $0.98^{*}$ & $0.40^{*}$ & 14.06 & 12.43 & 43.27 \\
\hline 0.30 & 0.20 & $3.32^{*}$ & $3.19^{*}$ & 19.81 & 18.00 & 43.31 \\
\hline 0.30 & 1.00 & 26.02 & 25.29 & 32.69 & 34.37 & $4.71^{*}$ \\
\hline 0.40 & 0.00 & 6.45 & $4.45^{*}$ & 12.23 & 10.73 & 19.63 \\
\hline 0.40 & 0.10 & $3.30^{*}$ & $2.70^{*}$ & 17.98 & 15.68 & 19.12 \\
\hline 0.40 & 0.70 & 34.13 & 23.32 & 31.40 & 31.13 & $5.73^{*}$ \\
\hline 0.40 & 0.80 & 26.00 & 25.28 & 31.98 & 32.02 & $5.08^{*}$ \\
\hline 0.40 & 0.90 & 27.50 & 26.85 & 32.64 & 32.80 & $5.11^{*}$ \\
\hline 0.50 & 0.00 & 7.49 & $5.84^{*}$ & 15.38 & 13.12 & 7.89 \\
\hline 0.50 & 0.10 & 6.14 & $5.83^{*}$ & 21.44 & 18.62 & 6.30 \\
\hline 0.50 & 0.20 & 11.24 & 11,36 & 27.34 & 24.62 & $5.81^{*}$ \\
\hline 0.50 & 0.30 & 18.20 & 18.46 & 32.72 & 30.33 & $5.86^{*}$ \\
\hline 0.60 & 0.00 & 8.59 & 7.38 & 18.23 & $15 . .40$ & $2.70^{*}$ \\
\hline 0.60 & 0.10 & 9.02 & 9.15 & 24.48 & 21.31 & $1.00^{*}$ \\
\hline 0.60 & 0.20 & 15.22 & 15.70 & 30.31 & 27.36 & $1.25^{*}$ \\
\hline 0.60 & 0.30 & 22.70 & 23.22 & 35.51 & 32.95 & $2.59^{*}$ \\
\hline 0.60 & 0.40 & 29.91 & 30.36 & 40.08 & 37.95 & $4.70^{*}$ \\
\hline 0.70 & 0.00 & 9.77 & 9.00 & 20.82 & 17.60 & $1.22^{*}$ \\
\hline 0.70 & 0.10 & 12.04 & 12.49 & 27.15 & 23.80 & $0.04^{*}$ \\
\hline 0.70 & 0.20 & 19.01 & 19,76 & 32.86 & 29.84 & $1.26^{*}$ \\
\hline 0.70 & 0.30 & 26.72 & 27.46 & 37.85 & 35.28 & $3.77^{*}$ \\
\hline 0.80 & 0.00 & 11.09 & 10.73 & 23.20 & 19.75 & $1.72^{*}$ \\
\hline 0.80 & 0.10 & 14.97 & 15.66 & 29.54 & 26.13 & $1.39^{*}$ \\
\hline 0.80 & 0.20 & 22.57 & 23.51 & 35.10 & 32.10 & $3.57^{*}$ \\
\hline 0.90 & 0.00 & 12.57 & 12.58 & 25.41 & 21.85 & $3.19^{*}$ \\
\hline 0.90 & 0.10 & 17.86 & 18.77 & 31.70 & 28.33 & $3.82^{*}$ \\
\hline 1.00 & 0.00 & 14.22 & 14.56 & 27.49 & 23.90 & $5.05^{*}$ \\
\hline
\end{tabular}

The non-rejection values of the null hypothesis at the 5\% significance level are in bold and with an asterisk. 


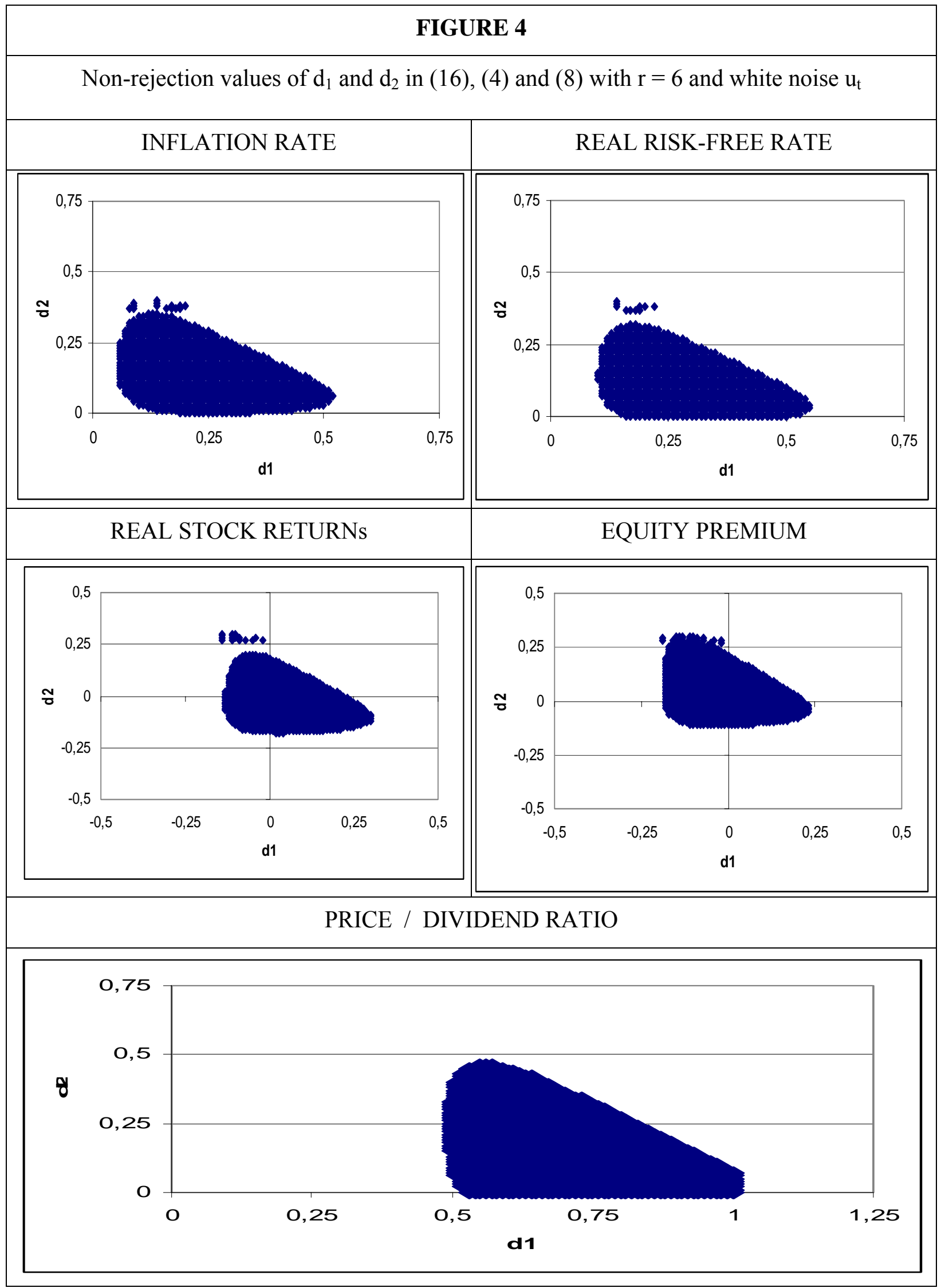




\section{TABLE 4}

Selected models for each time series

\begin{tabular}{|c|c|c|c|}
\hline $\begin{array}{l}\text { Models / } \\
\text { Series }\end{array}$ & $\begin{array}{l}\text { Fractional and cyclical differencing } \\
\qquad(\mathrm{FCD})\end{array}$ & $\begin{array}{l}\text { Fractional differencing } \\
\qquad(\mathrm{FD})\end{array}$ & $\begin{array}{l}\text { Integer differencing } \\
\text { (ID) }\end{array}$ \\
\hline $\begin{array}{l}\text { Inflation } \\
\text { rate }\end{array}$ & $\begin{array}{c}y_{t}=0.018+x_{t} \\
(0.006) \\
(1-L)^{0.17}\left(1-2 \cos w_{7} L+L^{2}\right)^{0.14} x_{t}=\varepsilon_{t}\end{array}$ & $\begin{array}{c}y_{t}=0.017+x_{t} \\
(0.009) \\
(1-L)^{0.19} x_{t}=u_{t} \\
u_{t}=0.21 u_{t-1}-0.11 u_{t-2}+\varepsilon_{t}\end{array}$ & $\begin{array}{c}y_{t}=0.020+x_{t} ; \\
(0.009) \\
x_{t}=0.38 x_{t-1}-0.06 x_{t-2} \\
+\varepsilon_{t}+0.291 \varepsilon_{t-1}\end{array}$ \\
\hline $\begin{array}{l}\text { Real risk } \\
\text { free rate }\end{array}$ & $\begin{array}{c}y_{t}=0.0348+x_{t} ; \\
(0.015) \\
(1-L)^{0.25}\left(1-2 \cos w_{6} L+L^{2}\right)^{0.10} x_{t}=\varepsilon_{t}\end{array}$ & $\begin{array}{c}y_{t}=0.021+x_{t} \\
(0.011) \\
(1-L)^{0.04} x_{t}=u_{t} \\
u_{r}=0.35 u_{t-1}+\varepsilon_{t}\end{array}$ & $\begin{aligned} y_{t}= & 0.016+x_{t} \\
& (0.007) \\
x_{t}= & 0.381 x_{t-1}+\varepsilon_{t}\end{aligned}$ \\
\hline $\begin{array}{l}\text { Real stock } \\
\text { returns }\end{array}$ & $\begin{array}{c}y_{t}=0.0970+x_{t} \\
(0.056) \\
(1-L)^{-0.05}\left(1-2 \cos w_{5} L+L^{2}\right)^{0.05} x_{t}=\varepsilon_{t}\end{array}$ & $\begin{array}{c}y_{t}=0.0971+x_{t} \\
(0.019) \\
(1-L)^{0.01} x_{t}=u_{t} \\
u_{r}=0.012 u_{t-1}+\varepsilon_{t}\end{array}$ & $\begin{array}{c}y_{t}=0.0970+\varepsilon_{t} \\
\quad(0.016)\end{array}$ \\
\hline $\begin{array}{c}\text { Equity } \\
\text { premium }\end{array}$ & $\begin{array}{c}y_{t}=0.0580+x_{t} ; \\
(0.004) \\
(1-L)^{-0.06}\left(1-2 \cos w_{6} L+L^{2}\right)^{0.03} x_{t}=\varepsilon_{t}\end{array}$ & $\begin{aligned} y_{t}= & 0.0546+x_{t} \\
& (0.003) \\
& (1-L)^{-0.04} x_{t}=\varepsilon_{t}\end{aligned}$ & $\begin{array}{c}y_{t}=0.0574+x_{t} \\
\quad(0.01) \\
x_{t}=\varepsilon_{t}+ \\
0.176 \varepsilon_{t-1}-0.239 \varepsilon_{t-2}\end{array}$ \\
\hline $\begin{array}{l}\text { Price-- } \\
\text { Dividend } \\
\text { ratio }\end{array}$ & $\begin{array}{c}y_{t}=18.811+x_{t} ; \\
(6.679) \\
(1-L)^{0.68}\left(1-2 \cos w_{6} L+L^{2}\right)^{0.09} x_{t}=\varepsilon_{t}\end{array}$ & $\begin{aligned} y_{t}= & 18.762+x_{t} ; \\
& (6.123) \\
& (1-L)^{0.73} x_{t}=\varepsilon_{t}\end{aligned}$ & $\begin{array}{l}(1-L) y_{t}=0.163+x_{t} \\
\quad(0.018) \\
x_{t}=\varepsilon_{t}+ \\
\quad-0.078 \varepsilon_{t-1}-0.340 \varepsilon_{t-2}\end{array}$ \\
\hline
\end{tabular}

Standard errors are in parentheses. 
TABLE 5

Overall ranking of forecasting performance using different criteria

\begin{tabular}{|c|c|c|c|c|c|c|c|}
\hline Series & Model & Theil's U & MAPE & MSE & RMSD & RMSE & MAD \\
\hline \multirow{3}{*}{ Inflation rate } & FCD & 2 & 1 & 1 & 1 & 1 & 1 \\
\hline & FD & 1 & 2 & 2 & 2 & 2 & 3 \\
\hline & ID & 3 & 3 & 3 & 3 & 3 & 2 \\
\hline Real risk & FCD & 1 & 1 & 1 & 1 & 1 & 1 \\
\hline \multirow{2}{*}{ free rate } & FD & 3 & 3 & 3 & 3 & 3 & 2 \\
\hline & ID & 2 & 2 & 2 & 2 & 2 & 3 \\
\hline Real stock & FCD & 3 & 3 & 3 & 3 & 2 & 3 \\
\hline \multirow{2}{*}{ return } & FD & 2 & 2 & 2 & 2 & 3 & 2 \\
\hline & ID & 1 & 1 & 1 & 1 & 1 & 1 \\
\hline \multirow[t]{2}{*}{ Equity } & $\mathrm{FCD}$ & 3 & 3 & 3 & 3 & 3 & 3 \\
\hline & FD & 1 & 2 & 2 & 2 & 2 & 1 \\
\hline premium & ID & 2 & 1 & 1 & 1 & 1 & 2 \\
\hline \multirow{3}{*}{ Price - Dividend } & $\mathrm{FCD}$ & 2 & 1 & 1 & 1 & 1 & 2 \\
\hline & FD & 1 & 2 & 2 & 2 & 2 & 1 \\
\hline & ID & 3 & 3 & 3 & 3 & 3 & 3 \\
\hline
\end{tabular}

FCD stands for Fractional and Cyclical Differentiation, FD for Fractional Differentiation, and ID for Integer Differentiation. 
TABLE 6

Selected models for Inflation and Price/Dividend ratio (1871 - 1978)

\begin{tabular}{|l|c|c|c|}
\hline & FCD & FD & ID \\
\hline Inflation & $y_{t}=0.018+x_{t} ;$ & $\begin{array}{c}y_{t}=0.016+x_{t} ; \\
(0.006)\end{array}$ & $\begin{array}{c}(0.011) \\
(0.009)\end{array}$ \\
& $(1-L)^{0.14}\left(1-2 \cos w_{7} L+L^{2}\right)^{0.16} x_{t}=\varepsilon_{t}$ & $\begin{array}{c}(1-L)^{0.24} x_{t}=u_{t} \\
u_{t}=0.14 u_{t-1}-0.12 u_{t-2}+\varepsilon_{t}\end{array}$ & $\begin{array}{c}x_{t}=0.36 x_{t-1}-0.07 x_{t-2} \\
+\varepsilon_{t}\end{array}$ \\
\hline $\begin{array}{l}\text { Price/ } \\
\text { Divid } \\
\text { end } \\
\text { ratio }\end{array}$ & $y_{t}=18.347+x_{t} ;$ & $\begin{array}{c}y_{t}=18.481+x_{t} ; \\
(6.702)\end{array}$ & $\begin{array}{c}(6.505) \\
(1-L) y_{t}=0.151+x_{t} ; \\
(0.018) \\
x_{t}=\varepsilon_{t}+ \\
+0.101 \varepsilon_{t-1}\end{array}$ \\
\hline
\end{tabular}

TABLE 7

MSE forecasts for inflation and price/dividend ratio

a) inflation

\begin{tabular}{|c|c|c|c|c|c|l|}
\hline & 1 period & 3 period & 6 period & 9 period & 12 period & 15 period \\
\hline FCD & 1.3732 & 1.6221 & $1.5902 *$ & 1.6114 & $1.6110^{*}$ & $1.7071^{*}$ \\
\hline FD & $1.2165^{*}$ & 1.4093 & 1.7735 & 1.6551 & 1.6895 & 1.8112 \\
\hline ID & 1.3233 & 1.3921 & 1.7483 & 1.6643 & 1.7420 & 1.9921 \\
\hline
\end{tabular}

a) price/dividend ratio

\begin{tabular}{|c|c|c|c|c|c|l|}
\hline & 1 period & 3 period & 6 period & 9 period & 12 period & 15 period \\
\hline FCD & 2.2819 & 2.0420 & $1.9617^{*}$ & $1.8447^{*}$ & $3.3683^{*}$ & $3.9035^{*}$ \\
\hline FD & 2.3850 & 2.1614 & 2.1920 & 2.9957 & 4.9017 & 4.8902 \\
\hline ID & 2.3480 & 1.7070 & 2.4346 & 2.1656 & 4.2935 & 5.1132 \\
\hline
\end{tabular}

